\title{
El marco teórico de la integración económica: revisión y propuesta
}

\section{The theoretical framework of economic integration: review and proposal}

\section{RESUMEN}

El artículo revisa las principales definiciones y teorías de la integración económica, enfatizando en la importancia y etapas del proceso. También se analiza la relación de la integración con las políticas nacionales y las nuevas teorías de la integración en el contexto global; con especial interés se revisa el denominado nuevo Regionalismo y la propuesta de Regionalismo Abierto de CEPAL. El autor hace una propuesta agregando a las conocidas etapas de la integración económica que presentó Bela Balassa a principios de los años sesenta del Siglo XX, una etapa intermedia de integración de organizaciones ciudadanas, para darle contenido social y político al proceso integrador.

Palabras clave: Integración Económica; Nuevo regionalismo; Regionalismo Abierto; Zona de Libre Comercio; Unión Aduanera; Mercado Común; Unión Económica; Integración total; Ciudadanía.

\begin{abstract}
The article reviews the main definitions and theories of economic integration, emphasizing the importance and stages of the process. It also discusses the relationship of integration with national policies and new theories of integration into the global context; with particular interest is the review of the so-called new Regionalism and ECLAC's Open Regionalism proposal. The author makes a proposal by adding to the well-known stages of economic integration presented by Bela Balassa in the early sixties of the twentieth century, an intermediate stage of integration of citizen organizations, to give it social and political content to the integrative process.
\end{abstract}

Keywords: Economic Integration; New regionalism; Open Regionalism; Free trade Area; Customs union; Common Market; Economic Union; Total Integration; Citizenship.
Enrique Cornejo Ramírez

ecornejor@unmsm.edu.pe

Universidad Nacional Mayor de San Marcos, Facultad de Ciencias Administrativas. Lima, Perú

Presentado: 01/03/2021 - Aceptado: 25/03/2021 - Publicado: 17/06/2021

(C) Los autores. Este artículo es publicado por la revista Gestión en el Tercer Milenio de la Facultad de Ciencias Administrativas Universidad Nacional Mayor de San Marcos. Este es un artículo de acceso abierto, distribuido bajo los términos de la licencia Creative Commons Atribución 4.0 Internacional (CC BY 4.0) [https://creativecommons.org/licenses/by/4.0/deed.es] que permite el uso, distribución y reproducción en cualquier medio, siempre que la obra original sea debidamente citada de su fuente original. 
Analizaremos, en primer lugar, el marco teórico en el que se desarrolla la integración. Desde su propia raíz etimológica se aprecia lo complejo del objetivo de la integración.

En el Diccionario de la Lengua Española se señala que la palabra "integración" proviene del latín "integratio" que significa "acción y efecto de integrase", es decir, "hacer que alguien o algo pase a formar parte de un todo". Real Academia Española (2001, p. 1288).

Pero ¿es tan sencillo integrar las partes en el todo? ¿Y qué hay de la individualidad de las partes? ¿Se trata de una simple suma de las partes o el todo resultante es un nuevo todo? Estas son algunas interrogantes que se plantean y que, sin duda, analizaremos en este ensayo. No se trata de homogenizar o uniformar, sino de sumar manteniendo cada quién su identidad y sus propias diferencias, lo que enriquece al todo resultante.

\section{Definición de la Integración}

Podemos definir la integración de la siguiente manera:

\section{Integración (Definición)}

"Proceso mediante el cual dos o más países deciden avanzar -gradual y conjuntamente- en su camino al desarrollo, unificando sus políticas en diferentes aspectos (comerciales, aduaneros, monetarios, financieros, migratorios, tecnológicos, educativos, de salud, de infraestructura física, de defensa, relaciones exteriores, entre otros), y siendo conscientes -todos- que, al avanzar, hay que ceder soberanía nacional y asumir costos a fin de obtener beneficios superiores para el bloque regional".

Nuestra definición empieza vinculando la integración a un proceso, que necesariamente toma su tiempo (la integración europea, por ejemplo, logró el mercado común después de 40 años de esfuerzos y negociaciones) y debe hacerse por etapas.

De otro lado, a la integración hay que mirarla con una visión integral (y no sólo comercial o sólo política) porque incluye todos los aspectos de la política pública y porque el de- sarrollo, que es el fin último que se busca, debe enfocarse de manera integral.

Por otra parte, nuestra definición llama la atención sobre el presupuesto que debe estar muy claro en todos los actores involucrados desde el comienzo: cada paso que se da implica menos grados de libertad para los gobiernos nacionales y un análisis costo/beneficio que debe ser ponderado en función de los intereses de todo el bloque regional.

Sin embargo, la definición de integración ha ido variando en el último siglo, desde concepciones muy simplistas y acotadas al tema comercial, hasta definiciones más complejas, teniendo en cuenta la propia experiencia que los países han venido teniendo en su participación en diferentes bloques regionales de integración.

También las definiciones de integración varían según la posición ideológica de los autores. Aquellos autores que están más vinculados a posiciones liberales y ortodoxas desde el punto de vista económico plantean generalmente definiciones laxas en las que la integración se puede ver como necesaria, pero es el libre comercio, a través de la acción multilateral de los países, lo que debe promoverse.

Por el contrario, existen posiciones más enfocadas en una crítica -explícita o implícita- a la teoría clásica del libre comercio o que tiene en cuenta la realidad de los países menos desarrollados. Estas posiciones heterodoxas tienden a dar mayor importancia al proceso de integración regional, como un esfuerzo conjunto que varios países realizan a fin de lograr mejores niveles de bienestar para su población.

Sin embargo, en los albores del Siglo XXI, parecen converger unas posiciones y otras. En la literatura económica se habla ahora del Nuevo Regionalismo y, en América Latina, la Comisión Económica para América Latina (CEPAL) se refiere al Regionalismo Abierto, ambos planteamientos coinciden en una aproximación entre los objetivos del libre comercio (multilateralismo) y los de la integración (regionalismo), siendo que, como hemos dicho, el objetivo final es el mismo: lograr avanzar en el proceso de desarrollo de los países y en el mayor bienestar de sus ciudadanos. 
Hay que señalar que la integración, desde una perspectiva más integral, no sólo tiene que ver con aspectos económicos, sino también con aspectos políticos, sociales y culturales. Vergara (1997) señala que "el poder político es el motor de los procesos de integración política y sin su intervención efectiva y permanente estos fracasan" (p. 82).

Define luego la "integración social" como "la superación de las divergencias entre élites y masas, entre gobernantes y gobernados" (Vergara, 1997, p. 82).

Finalmente, define la "integración cultural" que busca "superar el aislamiento cultural de los países del área, intensificando la comunicación y la cooperación entre ellos...es el esfuerzo de intercomunicar las expresiones de las culturas de las naciones de la región" (Vergara, 1997, p. 82).

Vergara sostiene que ha sido necesaria una larga evolución del pensamiento social para reconocer la dimensión cultural de los procesos de desarrollo e integración. Esto no significa, de ninguna manera, intentar uniformizar la cultura de los diferentes países, ni borrar sus diferencias nacionales. Precisamente, el reto que plantea la integración es lograr la unidad en medio de la diversidad.

Sobre estos conceptos volveremos más adelante; por ahora analizaremos la evolución del concepto de la integración, en un principio, fundamentalmente vinculado a los aspectos económicos y después ya considerando una gama de aspectos del desarrollo.

\section{La evolución del concepto de la Integración}

Lo que podríamos denominar la "teoría clásica de la integración económica" está muy vinculada al examen de los acuerdos de integración que se experimentan en las décadas del cincuenta y del sesenta del Siglo XX y a la explicación que se puede hacer de estos acuerdos desde la óptica de la teoría clásica del comercio internacional.

El economista canadiense de origen rumano, Jacob Viner (1892-1970), de la Escuela de Chicago nos recuerda los fundamentos de la teoría económica clásica:
La escuela clásica trabajó con los supuestos siguientes: que los hombres, incluidos los gobernantes, actuaban racionalmente; que el principal objetivo económico de los hombres racionales que requería decisiones de política nacional para su consecución era la promoción de la prosperidad económica, y que los mejores medios para alcanzar aquel fin eran la libertad de empresa en el ámbito nacional y el libre comercio en el internacional. (Viner, 1966, p. 23).

De esta manera, los primeros esfuerzos de integración fueron vistos fundamentalmente en cuanto a su impacto en el libre comercio y el beneficio neto que supone establecer ciertas medidas proteccionistas al interior del bloque frente a la pérdida de bienestar por dejar de apostar por las ventajas del comercio libre a nivel multilateral. El propio Viner y otros autores se referían al impacto del establecimiento de zonas de libre comercio y uniones aduaneras principalmente en Europa y América Latina.

En esos años (mediados del Siglo XX) ya se apreciaban cambios importantes de la economía mundial que ponían en discusión la teoría clásica del comercio internacional, como por ejemplo, el declive de la competencia y de la flexibilidad de los precios; el desarrollo de la planificación central sobre todo en países de Europa del Este; la creación de nuevos organismos internacionales en el campo económico como el FMI y el Banco Mundial (1944) y el Acuerdo General de Tarifas y Comercio (conocido por sus siglas en inglés: GATT) (1947), así como las agencias derivadas del programa norteamericano de ayuda a Europa (en el marco del denominado "Plan Marshall"). Entre estos cambios también se apreciaban en esos años mayores barreras al comercio internacional y es en ese contexto que surgen también los acuerdos de integración.

Veamos a continuación, diferentes definiciones de "integración" de acuerdo con varios autores y empezando por quien se considera uno de los autores clásicos en la teoría de la integración económica, el economista húngaro, Bela Balassa (1928-1991), profesor de la Universidad de Yale en los EE.UU. 
Observaremos que la mayoría de las definiciones de "integración económica" que encontramos en la literatura especializada enfatizan en los aspectos comerciales de la integración. El concepto irá evolucionando con el tiempo, incorporando otros aspectos en un contexto mundial cada vez más interdependiente.

Balassa (1961) escribió a principios de la década del sesenta su famoso libro "Teoría de la Integración Económica”, preocupado por darle una base teórica al proceso de integración europea que ya se estaba desarrollando desde la década anterior.

La integración europea surgió fundamentalmente, no como resultado de un debate teórico, sino por la necesidad de los países europeos de construir bases para el desarrollo y la paz, de manera que no se vuelvan a generar la condiciones para una nueva guerra mundial, recordando que las dos conflagraciones mundiales se iniciaron precisamente en el continente europeo.

Balassa sostenía que las consecuencias económicas de un proceso de integración tienen que analizarse sobre supuestos dinámicos, debido a la importancia que esta tiene en el crecimiento económico y plantea "una teoría unificada de integración económica que incluyera... los aspectos dinámicos de la integración económica y reuniera los problemas teóricos provenientes de la coordinación en las políticas económicas de una unión" (Balassa, 1961, p. VII).

Balassa define la integración considerándola primero como un proceso y luego como una situación de la actividad económica:

\section{Integración Económica (Definiciones, según Bela Balassa)}

Considerada como un proceso, la integración se encuentra acompañada de medidas dirigidas a abolir la discriminación entre unidades económicas pertenecientes a diferentes naciones.

Considerada como una situación de la actividad económica, la integración se caracteriza por la ausencia de varias formas de discriminación entre economías nacionales.

Fuente: BALASSA (1961, p. 1)
La o las definiciones de integración económica planteadas por Balassa parten del supuesto de que la discriminación -en cualquiera de sus formas- es perjudicial para la actividad económica, y, que, para que haya discriminación, tienen que haber necesariamente relaciones comerciales entre los países.

Para aclarar aún más sus conceptos, Balassa distingue entre cooperación económica e integración económica. La diferencia, para el autor, es muy clara: la cooperación económica implica disminuir la discriminación, mientras que la integración económica supone eliminar toda forma de discriminación.

En este sentido, dos o más países pueden tener acuerdos bilaterales de cooperación económica (incluidos los aspectos comerciales), pero, si deciden eliminar (progresivamente, pero eliminar) las barreras comerciales que tienen entre sí, entonces ya nos encontramos en el campo de la integración económica, como lo veremos más adelante.

Podríamos esquematizar lo señalado hasta el momento de la siguiente manera, primero los países buscan cooperar entre sí en diversos temas, después avanzan hacia esquemas de integración de los mismos que van logrando una mayor profundización conforme se avanza en las diferentes etapas, hasta llegar finalmente a la unificación de los referidos países.

COOPERACIÓN--NTEGRACIÓN--UNIFICACIÓN.

En la Tabla 1 mencionamos algunos de los principales organismos internacionales de cooperación internacional entre países.

Los organismos internacionales mencionados funcionan hace varias décadas buscando la cooperación internacional en campos tan variados como la economía, las finanzas, la salud, la educación, el comercio, la alimentación o la infancia. Son sólo algunos ejemplos y hay también organismos de cooperación internacional de muchos gobiernos nacionales que trabajan muy activamente en el desarrollo económico y social, como es el caso de los EE.UU. (AID), Japón (JICA), Alemania (GIZ), Suiza (SECO), Corea del Sur (KOIKA), Canadá (ACDI) o la Agencia 
Tabla 1

Ejemplos de Organismos de Cooperación Internacional, 2019

Nombre (Año de creación, No. de Países Miembros, Sede)

- $\quad$ Organización de las Naciones Unidas (ONU); 1945, 193 países; Nueva York-EE.UU.

- $\quad$ Fondo Monetario Internacional (FMI); 1945; 189 países, Washington-EE.UU.

- $\quad$ Organización de las Naciones Unidas para la Alimentación y la Agricultura (FAO); 1945, 197 países, Roma-Italia.

- $\quad$ Organización de las Naciones Unidas para la Educación, la Ciencia y la Cultura (UNESCO); 1945, 195 países, París- Francia

- $\quad$ Fondo de las Naciones Unidas para la Infancia (UNICEF); 1946, 191 países, Nueva York-EE.UU.

- $\quad$ Organización Mundial de la Salud (OMS); 1948, 196 países, Ginebra-Suiza.

- $\quad$ Comisión Económica para América Latina (CEPAL); 1948, 46 países, Santiago de Chile.

- Organización para la Cooperación y el Desarrollo Económico (OCDE); 1961, 36 países, París-Francia

- Conferencia de las Naciones Unidas sobre el Comercio y Desarrollo (UNCTAD); 1964, 194 países, Ginebra-Suiza.

- Organización Mundial del Comercio (OMC); 1995, 164 países, Ginebra-Suiza.

Nota: Elaborado por el autor

Española de Cooperación Internacional para el Desarrollo, entre otros.

Obsérvese que todos los organismos multilaterales de cooperación tienen una alta membresía (afiliación casi universal), siendo la Organización Mundial de la Salud (OMS) la que cuenta con el mayor número de países miembros: 196.

En todos los casos, la cooperación es una ayuda de país a país o grupo de países, pero no es integración. La integración supone mucho más.

Balassa hace referencia también a la relación entre la integración y los factores políticos. Dice el autor:

Los motivos políticos pueden impulsar la primera etapa de la integración económica, pero también ésta reacciona en la esfera política; si los motivos iniciales son económicos, la necesidad de una unidad política puede plantearse en una etapa ulterior. (Balassa, 1961, p. 7)

Sin embargo, para Balassa, desde el punto de vista económico, la cuestión básica no es si fueron económicas o políticas las motivaciones que dieron el primer impulso a la integración, sino cuáles serán los efectos económicos de la integración.

Balassa (1961) señalaba que, en algunos círculos políticos, los aspectos económicos son deliberadamente minimizados "y el plan de la integración se considera simplemente como un peón en el juego de las fuerzas políticas".
En este caso, está claramente la experiencia de los países socialistas con el CAME o COMECOM. También Balassa analizaba el caso de los Estados Unidos de América, cuya integración fue el resultado de motivaciones políticas, pero con importantes fundamentos económicos desde el inicio.

En nuestro libro sobre "Comercio Internacional" (Cornejo, 2010), citando a Balassa señalaba que:

La teoría de la integración económica se interesa por los efectos económicos de la integración en sus diversas formas y en los problemas generados por las divergencias en las políticas nacionales, de orden monetario, fiscal y otras diversas. (p. 235)

De otro lado, para Case y Fair (1993), "la integración económica se presenta cuando dos países o más se unen para formar una zona de libre comercio" Case/Fair (1989, p. 989). Esta definición, bastante simplista, se limita a la constitución de un área de libre comercio en la que se eliminan los aranceles entre sí.

H. Robert Heller (1968), profesor de la Universidad de California, se refiere a las uniones aduaneras como

Macario Schettino (1996), economista de El Colegio de México, señala que:

un grupo de países entra a una asociación económica, o, a un acuerdo preferencial, cuando decide reducir sus tarifas entre ellos con relación a las que 
operan contra el resto del mundo... cuando se establece la unión (aduanera), se construye una cápsula alrededor de ellos (los países miembros), de forma que son percibidos como una sola entidad por el resto del mundo.

Miltiades Chacholiades (1992), economista norteamericano, nacido en Chipre y profesor de la Georgia State University, también tiene una aproximación parecida al tema en su libro "Economía Internacional" cuando nos dice que: "El enfoque regional...comprende los acuerdos entre un pequeño número de países, cuyo propósito es establecer el libre comercio entre ellos, manteniendo las barreras al comercio con el resto del mundo" y considera que estos acuerdos plantean un comercio preferencial.

Juan B. García- Sordó (2007) define la integración como un proceso destacando la importancia del tamaño del mercado y considerando la implicancia política que tiene cuando el proceso va avanzando.

Integración (Definición, según García-Sordó)

"Es un proceso a través del cual dos o más mercados nacionales de dimensiones poco adecuadas se unen para formar uno solo de una dimensión más conveniente...El progreso de la integración económica impone una coordinación política más estrecha, cuya profundización por lo general desemboca en una unión política”..

Fuente: GARCÍA SORDÓ (2007, p. 51).

Dominick Salvatore (1977), economista norteamericano de origen italiano y profesor de la Universidad de Fordham en Nueva York, nos da una definición un poco más amplia de la integración, entendiéndola como:

Integración Económica (Definición, según Dominick Salvatore)

"La integración económica se refiere a la formación de un área de libre comercio, una unión aduanera, un mercado común o una unión económica entre un grupo de países"

Fuente: SALVATORE (1992, p. 127).
Salvatore llama la atención sobre que la mayor parte del análisis teórico en el Siglo XX giró en torno a las uniones aduaneras y recuerda, citando a Jacobo Viner (1950), otro autor clásico ya citado, que los efectos estáticos de una unión aduanera sobre el bienestar se miden en términos de creación y desviación de comercio.

Se denomina "creación de comercio" cuando la producción interna se reemplaza por importaciones provenientes de un país miembro de la unión aduanera (o, socio del acuerdo de integración) que produce a menor costo y es más eficiente, lo cual incrementa el bienestar general.

De otro lado, hay "desviación de comercio" cuando las importaciones de un país no miembro de la unión, que produce a menor costo, se reemplazan por bienes provenientes de un país que es parte de la unión aduanera y produce a costos más altos, lo que reduce el bienestar general.

En lo que se refiere a los efectos dinámicos de una unión aduanera sobre el bienestar, estos son el resultado de una mayor competencia, de economías de escala, cambios tecnológicos y del mayor nivel de inversiones que se produce como consecuencia de la integración económica.

Juan Tugores (1994), profesor y rector de la Universidad de Barcelona, define la integración de la siguiente manera:

\section{Integración Económica (Definición según Tugores)}

La integración económica es el proceso mediante el cual se van eliminando, para los países miembros, características diferenciales tales como: barreras arancelarias y medidas paraarancelarias; limitaciones al desplazamiento de un país al otro de factores productivos como trabajo y capital; políticas industriales, tecnológicas, de competencia; alteraciones en los regímenes cambiarios; políticas monetarias y fiscales.

Fuente: TUGORES (1994, p. 123).

Como veremos más adelante, la integración económica es mucho más que los temas de integración comercial; incluso implica temas en otros ámbitos como el social y político. Pero en 
la teoría económica, las definiciones que estamos sistematizando coinciden en privilegiar los temas comerciales, dado que las primeras etapas del proceso de integración enfatizan precisamente en los aspectos comerciales.

De otro lado, el desatacado economista norteamericano Paul R. Krugman (1994), famoso por sus estudios de comercio internacional y Premio Nóbel de Economía 2008, en su texto clásico "Economía Internacional", llama la atención sobre los beneficios netos del proceso y define la integración económica como:

\section{Integración Económica (Definición, según} Krugman)

\begin{abstract}
“...aquella situación en la que determinadas naciones establecen acuerdos preferenciales $y$, en ellos, los aranceles aplicados a los productos precedentes de cada una de dichas naciones son menores a las tasas aplicadas a los mismos bienes procedentes de otros países. El caso más sencillo es aquél en el que dos o más países eliminan todos los aranceles en el comercio realizado entre sí, mientras continúan manteniendo las barreras arancelarias frente al resto del mundo. Tales acuerdos son conocidos como uniones aduaneras, mercados comunes y áreas de libre comercio."
\end{abstract}

Fuente: KRUGMAN, Paul R.../OBSTFELF, Maurice (1994, p. 262).

Krugman tiene una posición no tan entusiasta y más bien pragmática sobre la importancia de la integración o de los acuerdos regionales. Krugman distingue entre reducciones arancelarias generales (que se dan en el marco del libre comercio y la negociación multilateral) y reducciones arancelarias preferenciales (que se dan en el marco de los acuerdos de integración).

Señala el autor: "En principio, puede parecer que las reducciones arancelarias preferenciales son también positivas, aunque no tanto como la reducción general de aranceles. Pero, al fin y al cabo, ¿no es mejor medio pan que nada?" Krugman (1994, p. 262).

Debemos señalar que esta visión de la integración como la "segunda opción" frente al libre comercio (multilateralismo) también la vamos a encontrar en otros autores, pues algunos de ellos siguen pensando que, en esencia, la integración es una manera de discriminación en el comercio internacional, que limita sus beneficios.

Es así que la concepción de la integración como una política "de medio pan" revela la preferencia de Krugman por el libre comercio antes que por la integración. Sin embargo, hay que señalar que Krugman da estos argumentos a principios de los años noventa, cuando el único bloque sólido de integración era la entonces Comunidad Económica Europea (CEE) (hoy Unión Europea), que todavía no había completado la etapa del mercado común. Por ello, además, la visión que tiene de la integración está relacionada sólo al ámbito del comercio. Todo ello ha variado en décadas posteriores.

El beneficio final de un acuerdo de integración dependerá -señala Krugman- si se crea o se desvía comercio (como ya se ha mencionado). Nos dice el Premio Nóbel:

algunos grupos de países han negociado acuerdos comerciales preferenciales bajo los que reducen aranceles entre sí, pero no con respecto al resto del mundo. Los ejemplos más simples son los de las uniones aduaneras.

El valor económico de la integración en una unión aduanera es ambiguo. Si la integración conduce a reemplazar la producción nacional de alto coste por importaciones procedentes de otro país de la unión -el caso de la creación de comercio- el país gana. $\mathrm{Si}$, por el contrario, la integración conduce a reemplazar importaciones más baratas de fuera de la unión aduanera por importaciones más caras de dentro -el caso de la desviación de comercio- el país pierde. (Krugman, 1994, p. 262).

Por su parte, Ricardo Ffrench-Davis (1985), economista chileno, en su texto "Economía Internacional" define a la integración como:

Integración (Definición, según Ffrench-Davis)

“...la ampliación del espacio económico (...) que reviste gran significación para los países que disponen de mercados de dimensiones reducidas."

Fuente: Ffrench-Davis (1985, p. 412). 
Llama la atención sobre un asunto muy importante: el tamaño de las economías nacionales. Es claro que a todos los países -grandes y pequeños- les conviene participar más activamente de los beneficios del comercio internacional, pero, en el caso de los países de tamaño económico más pequeño, esa necesidad es aún mayor para lograr beneficiar a su población. La integración se convierte así en una alternativa para aprovechar mejor las ventajas del mercado ampliado.

\section{El autor agrega:}

La integración económica es visualizada por muchas naciones como el instrumento más indicado para lograr acceso a mercados más amplios, mejor conocidos y más estables, que promuevan tanto el crecimiento de las exportaciones como la sustitución de importaciones sobre una base regional. (Ffrench- Davis, 1985, p. 412).

Ffrench-Davis tiene una posición heterodoxa, que critica la versión neoclásica del crecimiento económico y del comercio internacional, en la que el libre comercio es considerado fundamental y, donde la integración se plantea como "una segunda opción".

Ffrench-Davis analiza también con claridad las diferencias entre creación y desviación de comercio que ya hemos mencionado anteriormente. Define la creación de comercio como "un traslado desde la producción nacional de alto costo, que estaba protegida por un derecho de aduana, a la producción de bajo precio de un país asociado." Ffrench- Davis (1985, p. 417).

De otro lado, la desviación de comercio queda definida como "...una transferencia de la fuente de intercambio desde zonas de bajo costo, situadas fuera de la Unión, hacia productores de costos altos situados dentro de ella" (Ffrench- Davis, 1985, p. 417).

Todo proceso de integración producirá entonces cierta desviación de comercio y alguna creación de comercio. El autor concluye entonces que: "El que la reducción de las trabas al intercambio entre los países de la Unión mejore la eficiencia en la asignación de recursos, dependerá de si los efectos de la creación de comercio sobrepasan los de la desviación de comercio" (Ffrench-Davis, 1985, p. 418). Queda claro el concepto.

En lo que respecta a la importancia de la "creación de comercio" y la "desviación de comercio", Bela Balassa sostiene que esta distinción es sólo un aspecto del problema, y prefiere referirse a los efectos positivos y negativos de producción, vinculando ambos conceptos a los costos involucrados en el proceso productivo.

Podemos llegar a la conclusión de que las expresiones "creación de comercio" y "desviación de comercio" cubren únicamente un aspecto de los efectos de producción, y para ser más exactos, debemos distinguir entre los efectos negativos y los positivos de la producción. (Balassa, 1961, p. 29).

Señala el autor que los efectos positivos de la producción se pueden definir como: "el ahorro en costos resultado de un cambio en las compras de fuentes de producción de costos altos a fuentes de bajos costos". Balassa (1961, pp. 29-30).

Por el contrario, los efectos negativos de la producción

se refieren al costo extra en la producción de una mercancía en el país miembro, y no en un país extranjero cuando la desviación de la fuente de oferta cambia de un productor de costo bajo (extranjero) a uno de costo alto (asociado). (Balassa, 1961, p. 30)

Con estas precisiones, Balassa concluye que la economía mundial, ganará o perderá, si los efectos positivos de producción son mayores o menores a los efectos negativos que se evidencien.

H. Robert Heller señala al respecto que:

Las ganancias totales derivadas de la creación de comercio tras la formación de la Unión Aduanera son el resultado de los efectos de producción y consumo. La magnitud de estos efectos depende principalmente de las siguientes variables: 1) el peso del arancel anterior a la unión; 2) la inclinación de la curva de 
oferta, y 3) la inclinación de la curva de demanda. Si el arancel previo a la unión es elevado, las ganancias derivadas de su abolición tienden a ser mayores". (Heller, 1973, p. 176)

Efectivamente, como señala Heller, hay una gran diferencia entre países que negocian un acuerdo de integración económica si el punto de partida esta dado por niveles arancelarios bajos a nivel nacional, entonces será más fácil (habrá que hacer menores sacrificios) llegar en algún momento al arancel cero o la eliminación de toda barrera arancelaria al interior del bloque regional. $\mathrm{Si}$, por el contrario, el punto de partida en las economías nacionales que buscan integrarse está dado por niveles promedio altos de aranceles o con muchas diferencias entre los países miembros, entonces el objetivo será más difícil de lograr.

Heller concuerda con los otros autores citados en que el efecto neto de una unión aduanera sobre el bienestar general estará dado por la diferencia existente entre los efectos de la creación y la desviación del comercio internacional. Concluye el autor:

“...la formación de una unión aduanera no conduce siempre al aumento del bienestar económico. Este hecho se encuentra claramente confirmado por el comportamiento observable de los países: algunos intentan formar uniones porque las ganancias esperadas son mayores que las pérdidas estimadas, mientras que otros renuncian a ello por las razones opuestas." Heller (1973, p. 178).

Finalmente, y para completar el panorama, nos parece esclarecedor también citar una definición de integración económica desde el punto de vista de una economía centralmente planificada o socialista.

Claramente, esta definición de integración económica está vinculada a un sistema de asignación de recursos de una economía planificada, en la que el Estado define qué y cómo producir y, obviamente, en cuanto a la integración, es el Estado el que también define la forma de participación de cada país en el bloque regional, de acuerdo a lo establecido en los correspondientes planes quinquenales.
Integración Económica (Definición, según el CAME)

"Proceso cuya finalidad es contribuir, mediante la unificación y la coordinación de los esfuerzos de los países miembros del Consejo, a profundizar y perfeccionar la colaboración y a desarrollar planificadamente la economía nacional, a acelerar el progreso económico y técnico de dichos países, a elevar el nivel de industrialización de los países industrialmente menos desarrollados, a incrementar ininterrumpidamente la productividad del trabajo, a acelerar e igualar paulatinamente los niveles de desarrollo económico y a elevar de modo constante el bienestar de los pueblos de los países miembros del Consejo."

Fuente: Muñiz (1986, p. 20).

Dice Muñiz Ortega: "La división socialista internacional planificada del trabajo contribuye a aprovechar al máximo las ventajas del sistema socialista mundial, establecer proporciones acertadas en la economía nacional de cada país." Muñiz (1986, p. 24).

En la práctica, esta experiencia de integración, que se materializó en el CAME, liderado por la entonces Unión de Repúblicas Socialistas Soviéticas (URSS), dejó de funcionar luego de la caída del Muro de Berlín en 1989 y de los profundos cambios que se dieron en la entonces Europa socialista, como consecuencia del Glasnost (transparencia) y la Perestroika (reestructuración), procesos que no sólo tuvieron influencia en esos países, sino que generaron un punto de inflexión en la historia de la economía mundial.

Como señala Sara González (1993):

“...el Consejo de Asistencia Económica Mutua (CAME), creado en 1949, por iniciativa de Stalin como respuesta al Plan Marshall, firmó su disolución en la 46ํㅜㅇ sesión, celebrada en Budapest el 28 de junio de 1991". Gonzáles (1993, p. 222).

De las varias definiciones antes mencionadas, se concluye que hay consecuencias positivas y negativas del proceso de integración; el arte de la política pública consistirá en encontrar el adecuado balance entre ambas, de manera de tener un resultado neto positivo. 
Y en nuestra opinión, aquí el papel del liderazgo del bloque y de los países miembros es fundamental, porque la vida -como la economía y la integración- no está hecha de colores blancos puros o de colores oscuros puros, sino de una variedad de grises que hay que saber interpretar y conducir. ¿Cuál es el gris adecuado para tal proceso de integración teniendo en cuenta el contexto y las circunstancias específicas en que se desarrolla? He ahí la cuestión clave para el éxito de las políticas públicas.

En la Tabla 2 sistematizamos las definiciones de los diferentes autores que hemos mencionado, destacando los conceptos sustanciales incluidos en cada una de ellas.

A continuación, analicemos lo que señala la teoría con respecto a la importancia del proceso de integración.

\section{Importancia de la Integración}

Citando nuevamente a Bela Balassa, recordaremos que el objetivo final de la actividad económica es una mejora en el bienestar de los ciudadanos. Por lo tanto, para ponderar la importancia de la integración, será necesario establecer cuál es su contribución al bienestar general.

Balassa sostiene que,

"En el caso de la integración, el bienestar económico quedará afectado: a) por un cambio en el volumen cuantitativo de artículos producidos; b) por un cambio en el grado de discriminación entre bienes nacionales y extranjeros; c) por una redistribución de ingresos entre los nacionales de diferentes países; y, d) por una redistribución dentro de los países individuales" Balassa (1961, pp. 11-12).

Para R. Ffrench-Davis, la integración es importante por cinco razones, que se presentan en la Tabla 3.

Tabla 2

Conceptos sustanciales en diferentes definiciones de integración

\begin{tabular}{ll}
\hline Autor & \multicolumn{1}{c}{ Concepto } \\
\hline Balassa & Proceso que elimina discriminación entre países \\
Krugman & Acuerdos preferenciales entre Países Miembros \\
Tugores & Eliminar características diferenciales entre países \\
Ffrench-Davis & Ampliación del espacio económico entre países \\
Heller & Alto grado de interdependencia entre países \\
Schettino & Una sola entidad frente al resto del mundo \\
Case/Fair & Formar Zona de Libre Comercio \\
Chacholiades & Libre comercio entre Países Miembros con barreras para el resto del mundo \\
García-Sordó & Mercados de dimensiones poco adecuadas que forman uno sólo de dimensión más conveniente. \\
& Coordinación política \\
Salvatore & Área de Libre Comercio, Unión Aduanera, Mercado Común, Unión Económica. \\
CAME/Muñiz Ortega & Unificación y coordinación de esfuerzos planificadamente entre países \\
Cornejo Ramírez & Proceso de avance gradual y conjunto, camino al desarrollo, unificando políticas y cediendo soberanía.
\end{tabular}

Nota: Elaborado por el autor.

Tabla 3

Importancia de la integración, según Ffrench-Davis

Mejora el acceso a los mercados externos para productos cuya venta en los países desarrollados ofrece dificultades, pues la asociación de un grupo de países permite un acceso más expedito al mercado regional dado que se trata de países con un grado de industrialización relativamente similar;

Permite aprovechar las economías de escala pues se cuenta con países a los cuales dirigir su producción sin barreras a la importación; Establece condiciones propicias para que los países que poseen menor experiencia y un desarrollo más incipiente tengan oportunidad para aprender.

Los países socios del proceso de integración obtienen un poder de negociación conjunta que es mayor al que dispone cada uno en forma aislada; $y$,

Permite un mayor grado de independencia política internacional, por la aceleración del proceso de desarrollo y el incremento del poder conjunto.

Fuente: Elaborado por el autor sobre la base de FFRENCH-DAVIS (1985, pp. 413-415). 
Aun cuando, como ya señalamos, en las primeras décadas de las experiencias de integración el énfasis está en la integración meramente comercial, cada vez es más claro que el proceso de integración es integral y comprende todos los aspectos vinculados al desarrollo económico y social de un país.

Las razones que expone Ffrench-Davis son muy claras. De hecho, la ampliación del mercado (que supone la integración en sus primeras etapas) genera nuevas oportunidades para los negocios y -al mismo tiempo- plantea desafíos tales como producir con un tamaño mínimo eficiente mayor en esos mismos negocios, lo que supone el buscar formas asociativas más eficientes para poder producir y exportar competitivamente.

Efectivamente el proceso de integración genera asimismo condiciones de aprendizaje y lo que podríamos denominar como "plataformas piloto de acción" para muchas empresas (especialmente las de tamaño pequeño y mediano) que recién empiezan en su proceso de internacionalización y otorga mejores condiciones de negociación conjunta y mayor interdependencia entre los países miembros.

Por cierto, los acuerdos de integración son "ventanas de oportunidades"; permiten acceso pleno, mejores condiciones de negociación, menores costos de transacción, pero no aseguran por sí mismos que las empresas puedan aprovechar los acuerdos para desarrollar negocios concretos. Ello dependerá de que los productos o servicios que se negocien entre las empresas sean competitivos y que cuenten con las condiciones de precio, calidad, servicio y de oportunidad de entrega que exigen los mercados.

Los negocios internacionales no se concretan sólo porque hay buenos acuerdos comerciales o de integración, sino porque los acuerdos específicos a los que se lleguen benefician a todas las partes y, principalmente, a los consumidores finales.

De otro lado, la integración es importante en la medida en que contribuye efectivamente a mejorar las condiciones de vida de la población $y$, específicamente, a disminuir los niveles de pobreza y reducir la brecha de desigualdad entre países y, al interior de cada país, entre la población.
En tal sentido, Joseph E. Stiglitz (2005), Premio Nóbel de Economía 2001, llama la atención sobre este tema, al analizar la experiencia de México en su participación en el Acuerdo de Libre Comercio de América del Norte (conocido por sus siglas en inglés como NAFTA).

Dice Stiglitz:

"El objetivo de la integración económica debería ser elevar el nivel de vida, pero está claro que la liberalización comercial por sí misma no es suficiente para conseguirlo. No hay duda de que el comercio y la inversión son de vital importancia para el crecimiento económico pero el verdadero desafío es llevar a cabo la liberalización de modo que promueva un desarrollo sostenible, en el cual vean aumentar sus ingresos aquéllos que se encuentran en las capas medias y más bajas de la sociedad". Stiglitz (2005, p.54).

Para Stiglitz la globalización de fines del Siglo XX y principios del Siglo XXI no se basa precisamente en el "libre comercio", sino

"...en un comercio gestionado en favor de los intereses empresariales en Estados Unidos y en otros países avanzados, que trataba de equilibrar esos intereses, mientras que los acuerdos daban escasa importancia a los intereses de los otros, los trabajadores de los países avanzados y los de otros países" Stiglitz (2018, p. 64).

Y agrega el autor: "Por ejemplo, un acuerdo de libre comercio, en realidad, tiene poco que ver con el comercio libre". Stiglitz (2018, p. 64).

Stiglitz señala que si los acuerdos de libre comercio tuvieran efectivamente el objetivo que señala su nombre deberían ser acuerdos de redacción muy breve, en donde se señale claramente que cada país renuncia a sus barreras arancelarias, barreras no arancelarias y a sus subsidios, pero no es así, se trata más bien de lo que Stiglitz denomina "acuerdos de comercio gestionado".

Por ejemplo, recuerda que el Acuerdo Transpacífico de Cooperación Económica (TPP) tenía más de seis mil páginas y que los EE.UU. 
(nosotros agregamos a los países europeos) se han negado reiteradamente a reducir o eliminar sus subsidios agrícolas.

Afirma Stiglitz: "El descontento que provoca la globalización se ha centrado en acuerdos comerciales como el Tratado de Libre Comercio de América del Norte" (conocido como NAFTA). Stiglitz (2018, p. 67).

Recordando al mismo Stiglitz se puede señalar que la integración no sólo debería buscar un mayor y más sostenido crecimiento económico, sino que debería buscar que los frutos de ese proceso de crecimiento se queden al interior del bloque regional, es decir, que el producto nacional bruto (PNB) del grupo sea mayor al correspondiente producto bruto interno (PBI).

En la misma línea de pensamiento, en una publicación del Banco Interamericano de Desarrollo (BID) (1992), Enrique García, presidente de la Corporación Andina de Fomento (CAF) señalaba que, en la medida en que exista una coincidencia de enfoque a nivel de los países sobre la importancia de la integración, entonces ésta puede convertirse en un factor determinante para alcanzar los objetivos del proceso de desarrollo.

En efecto, la voluntad política y la coincidencia en los fundamentos de la política pública y en especial de la política económica, serán muy importantes para avanzar cualitativamente en el proceso de integración.

Por ejemplo, se avanzará más rápido en la integración si los países miembros del bloque tienen, como ya decíamos, más cercanos sus promedios arancelarios en el punto de partida de la negociación, si sus políticas macroeconómicas tienen los mismos criterios de manejo y si coinciden en políticas que promuevan la participación de la inversión privada nacional y extranjera.

García señala que la integración será relevante en la medida que se cumplen ciertos requisitos básicos (tres indispensables y cinco básicos no suficientes) que se muestran en la Tabla 4.

E. García sostiene así que la integración, a pesar de sus dificultades, es un proceso que considera irreversible a nivel regional y, aún desde las diferentes experiencias regionales, se avanza hacia una integración global.

Enrique V, Iglesias (1992), presidente del BID, refiriéndose a las diferentes experiencias de la integración en América Latina y El Caribe, afirmaba que:
"En América Latina hay una nueva inte- gración, no defensiva sino competitiva; una nueva integración para incorporar- nos al mercado mundial: una nueva in- tegración que es una red de seguridad frente a los avatares del mundo inter- nacional, pero que es también un apoyo a la reforma de la empresa y un anclaje a las reformas internas. Esa es la nueva integración que América Latina tiene hoy y que también queremos ver hacia el futuro." BID (1992, p. 133)

Hemos identificado catorce beneficios de la integración y señalamos que:

\section{Tabla 4}

Requisitos Básicos para que la Integración se convierta en un factor relevante para el desarrollo, según Enrique García

Básicos (Indispensables):

Que la ampliación del mercado y del espacio económico le permita un uso más eficiente de recursos y ventajas comparativas, aumentando de esta manera la competitividad y su inserción en la economía mundial.

Que su participación en un mecanismo de integración aumente su bienestar económico, por encima del que lograría en forma individual. Que le permita una participación más activa y equitativa en el plano internacional, así como en el diálogo y negociación con otras regiones o instituciones, ya sea en temas económicos, tecnológicos o políticos.

Básicos (no suficientes):

La adopción individual y colectiva de un marco de políticas económicas y de un modelo de desarrollo homogéneos.

El apoyo político al más alto nivel dentro de cada país participante.

El reconocimiento, por parte de los agentes económicos, de que el proceso de integración es beneficioso para su propio desarrollo.

La participación efectiva de los principales agentes económicos en el proceso: gobierno, empresarios y trabajadores, entre otros.

Tolerancia y flexibilidad para adaptarse a situaciones cambiantes y pa ra aceptar que un proceso de largo plazo tiene, necesariamente, dificultades en el corto plazo.

Fuente: BID (1992, pp. 38-39). 
“...lo más importante es que la integración no es un objetivo final, sino un proceso que permite lograr un crecimiento sostenido entre los países miembros (al mejorarse la eficiencia y la productividad, lo que redundará positivamente en el mercado de ahorro-inversión) y así contribuir al desarrollo integral de los mismos, mejorando la calidad de vida de la población involucrada". Cornejo (2010, p. 238).

En la Tabla 5 hemos identificado los principales beneficios de la integración:

El aprovechamiento de las economías de escala por la existencia de un mercado ampliado es un tema que ya destacaba Adam Smith en su famosa obra "Una Investigación sobre la naturaleza y causas de la riqueza de las Naciones" (1776). Smith señalaba claramente que una de las principales características diferenciales del sistema capitalista que emergía a mediados del Siglo XVIII, época en la que él escribía, era la existencia de la denominada "división del trabajo" o especialización.

No es casualidad que el capítulo 1 del libro I de su conocida obra empiece precisamente por este tema: "El mayor progreso de la capacidad productiva del trabajo y la mayor parte de la habilidad, destreza y juicio con que ha sido dirigido o aplicado, parecen haber sido los efectos de la división del trabajo". Smith (2009, p. 95).

Pero, rápidamente Adam Smith advierte que la principal limitación de la división del trabajo es el tamaño del mercado.
"Así como la capacidad de intercambiar da lugar a la división del trabajo, así la profundidad de esta división debe estar siempre limitada por la extensión de esa capacidad, o en otras palabras por la extensión del mercado". Smith (2009, p. 108).

En efecto, como ya lo advertía Smith hace casi 250 años, los países y las empresas tienden a crecer a través de un mayor comercio; cuando los mercados locales o nacionales ya están atendidos, el crecimiento se hará comerciando con otros países, es decir, el comercio internacional tiene su fundamento en el natural proceso de crecimiento de las empresas y de los países.

Siguiendo el razonamiento de Smith, para lograr un mayor y más sostenido comercio exterior, será necesario ampliar los mercados a través de los acuerdos multilaterales y de los acuerdos de integración, en tanto, ambos facilitan el más libre flujo de bienes y servicios al mundo en general y a los países del bloque regional en particular. Entonces, las economías de escala jugarán un papel importante.

Por la misma razón (la ampliación del mercado) y por la mayor interacción entre países, se tendrá que trabajar con mayor eficiencia, calidad y competitividad, reduciéndose los costos improductivos, reduciéndose los costos de transacción y construyéndose ventajas competitivas sostenibles basadas en estrategias de menores costos, de diferenciación o de alta segmentación.

\section{Tabla 5}

Los principales beneficios de la integración

Permite el aprovechamiento de las economías de escala;

Reduce de las rentas improductivas;

Reduce de los costos de transacción

Promueve la liberación comercial intrarregional;

Incentiva la creación y desviación de comercio;

Mejora las expectativas de los inversionistas;

Fomenta la incorporación del progreso técnico y la articulación productiva;

Permite la adquisición y difusión de información, capacitación y servicios financieros;

Implica un creciente flujo recíproco de personas, capital, información y tecnología;

Eleva la eficiencia en la toma de decisiones;

Fortalece la base institucional;

Contribuye a un crecimiento económico sostenido;

Mejora la calidad de vida de la población de los Países Miembros; y,

Mejora el bienestar mundial.

Fuente: CORNEJO (2010, p. 238). 
Ya hemos señalado que, con la integración se puede obtener un balance neto positivo entre la creación y la desviación de comercio y se puede también incrementar el comercio al interior del propio bloque regional.

De otro lado, mejoran las expectativas de los inversionistas para emprender nuevos proyectos que aprovechen las ventajas de la integración, disminuye el "riesgo país" que se consideraba a nivel de cada uno de los países y ahora se maneja como un "riesgo regional".

La innovación tecnológica se dinamiza con la integración y se produce lo que podría denominarse un "efecto contagio positivo" entre los países para adoptar estándares más altos (más exigentes) de calidad, sanidad, cuidado ambiental, aspectos laborales, etc.

Por ejemplo, cuando la entonces Comunidad Económica Europea (CEE) conformó finalmente un mercado común, una de las medidas estándares que se adoptaron en todo el bloque fue la elección del sistema inglés de aseguramiento de la calidad, conocido como ISO ${ }^{1}$, como el estándar europeo (común) obligatorio.

Como consecuencia de esa decisión comunitaria, todos los países miembros (y sus empresas) adoptaron el sistema ISO y, luego, todas las empresas no europeas que hacían negocios con el bloque tuvieron que adoptar el mismo sistema, y así sucesivamente, en un verdadero "efecto dominó".

Agregamos en este punto, un beneficio adicional a los que hemos mostrado en la Tabla $5 \mathrm{y}$ consiste en que, a través de la pertenencia a un acuerdo de integración, algunos aspectos culturales e históricos pueden convertirse en incentivos para desarrollar negocios entre empresas de diferentes países lo que antes del acuerdo no eran posibles.

1 En 1919, en Inglaterra, se constituyó la organización privada British Standards Institution (BSI). Ante la aparición de distintos organismos nacionales de normalización, surgió la necesidad de coordinar los trabajos y experiencias de todos ellos y con este objetivo se fundó en Londres en 1926 la International Federation of the National Standardizing Associations (ISA). Tras la Segunda Guerra Mundial, este organismo fue sustituido en 1947, por la International Organization for Standarization (ISO) u Organización Internacional para la Normalización, con sede en Ginebra y dependiente de la ONU. Esta familia de normas apareció en 1987, tomando como base la norma británica BS 5750 de 1987, experimentando su mayor crecimiento a partir de la versión de 1994, que fue adoptada como la norma comunitaria por el entonces Mercado Común Europeo (MCE).
Por ejemplo, el hecho que en el Perú viva la segunda colonia de inmigrantes japoneses en América Latina (después de la que reside en Brasil) y también una importante colonia de inmigrantes chinos, han sido factores determinantes no sólo para lograr sendos tratados de libre comercio o de asociación estratégica con ambos países (Japón y China) sino también para que el Perú pueda ingresar como miembro pleno del Foro de Cooperación Económica Asia-Pacífico (APEC).

Finalmente, la integración permite un mayor desarrollo institucional en los países miembros, todo lo cual contribuye a un mayor y mejor crecimiento económico, mejora de la calidad de vida de la población y mejora del bienestar mundial.

Desde un punto de vista regional, el estímulo a un mayor comercio intrarregional podría constituirse en factor fundamental para lograr la diversificación de productos y mercados, así como para lograr un mayor desarrollo y valor agregado en la producción manufacturera de los países involucrados.

Al respecto, un estudio de CEPAL acerca de las mejores políticas para la inserción de la región en la economía mundial concluye que

“...el comercio intrarregional, justamente por sus diferentes características, asociadas a la cercanía y a los vínculos de todo tipo que lo facilitan, resulta complementario de la inserción internacional global y representa un ámbito de dinamización del aprendizaje tecnológico, conducente a una mayor competitividad internacional y a un patrón más diversificado y equilibrado de especialización en la economía mundial." CEPAL (1994, pp. 84-85).

De acuerdo a las investigaciones de la CEPAL, el desarrollo de esfuerzos de producción y comercio intrarregional resulta positivo pero complementario al esfuerzo de inserción multilateral. De esta forma, la posición institucional de la CEPAL se va acercando al punto de vista del "Regionalismo Abierto", moderna tesis que sostiene ese organismo y en la que advierte que los esfuerzos multilaterales (libre comercio entre todos los países del mundo) y regionales 
(con bloques de integración) deben buscar la convergencia y no la divergencia.

\section{Las etapas de la Integración}

En nuestro libro sobre Comercio Internacional ya citado (Cornejo, 2010) presentamos las etapas de la integración sobre la base de las cinco citadas por Bela Balassa (1964).

Dice Balassa: “La integración económica..., puede adoptar varias formas que representan los grados diversos de integración. Estas son: área o zona de libre comercio, unión aduanera, mercado común, unión económica e integración económica total." Balassa (1964, p. 2).

El aporte teórico de Balassa ha sido fundamental -aunque existan algunos autores que no le quieran dar la importancia que se merece-, sobre todo porque lo planteó varias décadas atrás en un contexto mundial en el que la integración económica apenas empezaba a desarrollarse en algunas regiones del mundo. Cuando revisamos actualmente las diferentes experiencias de integración, con facilidad ubicamos el estado de avance teniendo en cuenta las etapas sugeridas por Balassa.

Por ejemplo, la Unión Europea -como su propio nombre lo sugiere- ya está en la cuarta etapa de unión económica (antes se denominaba Mercado Común Europeo cuando estaba en la tercera etapa y anteriormente se denominaba Comunidad Económica Europea, cuando era una Unión Aduanera). De otro lado, la Comunidad Andina y la Alianza del Pacífico se encuentran en la etapa de Zona de Libre Comercio ${ }^{2}$ y los denominados Tratados de Libre Comercio -cuyo número crece en todas las regiones del mundo- constituyen la expresión jurídica de una Zona de Libre Comercio.

Sin embargo, en ese mismo libro, le hemos agregado a los planteamientos de Balassa una "etapa preliminar" o "etapa cero" en la que señalamos que se crea el "ambiente" para el futuro acuerdo de integración propiamente dicho con el mutuo establecimiento -luego de negociaciones específicas- de preferencias o rebajas arancelarias entre países.

2 Aunque la Comunidad Andina tiene una Unión Aduanera aún no perfeccionada.
En la Tabla 6 presentamos estas etapas de la integración (incluyendo la agregada por nosotros) y colocamos en cada una de ellas el grado de avance que han logrado algunas de las experiencias de integración más conocidas en el mundo.

En la etapa preliminar que hemos agregado se encuentran los acuerdos que desarrollan los países latinoamericanos y del Caribe en el marco de la Asociación Latinoamericana de Integración (ALADI) ${ }^{3}$ y también los acuerdos en el marco del Foro Económico Asia-Pacífico (APEC) que incluye a los principales países de la Cuenca del Pacífico.

En la etapa de Zona de Libre Comercio, incluimos a los diversos acuerdos de libre comercio suscritos por los países en todas las regiones del mundo. Así, por ejemplo, el Perú, hacia el año 2019, tenía suscritos y ya en ejecución cerca de veinte tratados de libre comercio o acuerdos de asociación estratégica, que han impulsado decididamente la diversificación de su comercio exterior. En esta etapa también se encuentra el acuerdo regional denominado "Alianza del Pacífico" constituido inicialmente por Colombia, Chile, México y Perú.

Incluimos asimismo en esta primera etapa al Tratado Integral y Progresivo de Asociación Transpacífico (conocido por sus siglas en inglés como TPP), que es un tratado que busca rebajar las barreras arancelarias, establecer un marco común de propiedad intelectual y establecer un mecanismo de arbitraje de diferencias entre los diez países miembros: Vietnam, Japón, Canadá, México, Brunéi, Chile, Malasia, Australia, Singapur y Perú.

En la etapa de la Unión Aduanera se encuentran experiencias de integración como el Acuerdo de Libre Comercio de América del Norte (conocido inicialmente como NAFTA) que integran Canadá, México y los EE.UU. ${ }^{4}$, la Comunidad Andina $(\mathrm{CAN})^{5}$, el Mercado Común Cen-

3 Creada sobre la base de la Asociación Latinoamericana de Libre Comercio (ALALC) que surgió en la década de los años sesenta.

4 Acuerdo que fue muy criticado por el entonces candidato Donald Trump en su campaña presidencial y cuando ya estuvo en el ejercicio de la presidencia de los EE.UU. impulsó su renegociación.

5 Que se constituyó sobre la base del Acuerdo de Cartagena que se suscribió en 1969 con la participación de Bolivia, Colombia, Chile, Ecuador y Perú. Posteriormente se retiró Chile e ingresó Venezuela. Hacia el año 2019, sólo lo integran Bolivia, Colombia, Ecuador y Perú. 
Tabla 6

Etapas de la Integración y grado de avance de algunos procesos de integración

\begin{tabular}{lll}
\hline \multicolumn{1}{c}{ Bloques regionales } & \multicolumn{1}{c}{ Etapas } & \multicolumn{1}{c}{ Principal característica } \\
\hline Etapa preliminar o Etapa “cero" & Negociación de mutuas preferencias & ALADI, APEC. \\
Zona de Libre Comercio & Arancel Cero entre Países Miembros & $\begin{array}{l}\text { Diversos TLC's, TPP } \\
\text { Alianza del Pacífico } \\
\end{array}$ \\
Unión Aduanera & Arancel externo común frente a terceros & $\begin{array}{l}\text { Comunidad Andina } \\
\text { NAFTA, MCCA, }\end{array}$ \\
& Países & MERCOSUR \\
Mercado Común & Libre movilidad de todos los factores Productivos & ASEAN \\
Unión Económica & Armonización de políticas monetarias y fiscales, entre otras & Unión Europea (UE) \\
Integración total & Unificación de políticas. Un solo gobierno. Una sola Constitución. & EE.UU. \\
\hline
\end{tabular}

Nota: Elaborado por el autor sobre la base de Balassa (1964) y Cornejo (2010).

troamericano (MCCA), y el MERCOSUR (que integran Argentina, Brasil, Paraguay y Uruguay).

En la etapa del Mercado Común se encuentra, desde 2015, la Asociación de Naciones del Sudeste Asiático (conocida por sus siglas en inglés como ASEAN) e integrada por diez países: Birmania, Brunei, Camboya, Filipinas, Indonesia, Laos, Malasia, Singapur, Tailandia y Vietnam. Es curioso que algunos bloques como el MCCA o el MERCOSUR se denominen "mercado común" pero que no hayan alcanzado plenamente esta etapa de la integración. Es indudable que esta es ya una etapa superior en el proceso de la integración.

En la etapa de la Unión Económica destaca el bloque regional de la Unión Europea (UE) que, como ya señalamos, logró alcanzar este estadio de desarrollo luego de más de cuarenta años de esfuerzo negociador. La Unión Europea cuenta ya con un banco central común (el Banco Central Europeo-BCE), una moneda común (el Euro, que funciona en todas sus funciones: unidad de cuenta, medio de cambio y reserva de valor) y una política fiscal y presupuestal común.

Aún, con las dificultades que la experiencia europea de integración ha mostrado luego de los problemas en algunos países miembros para aprobar la Constitución Europea o del Brexit, sostenemos que se trata de uno de los esfuerzos de integración más avanzados y profundos del mundo.

Finalmente, en la quinta y última etapa -según la propuesta de Balassa- de la "integración total” se encuentran los Estados Unidos.
Se trata de un país federal, donde los cincuenta estados de la Unión tienen, cada uno, su propia constitución y sus leyes, pero coinciden en una Constitución Federal y en normas federales que los unen como una sola macro nación. En el futuro, la Unión Europea (UE) es posible que supere las dificultades actuales y llegue a la quinta etapa mencionada, en cuyo caso se pasaría a denominar los Estados Unidos de Europa (EUE).

La experiencia de los países que ya han adoptado acuerdos de integración nos indica que la secuencia de etapas sugerida por Bela Balassa en los años sesenta sigue siendo vigente en sus aspectos esenciales.

El mejor ejemplo de cumplimiento de las diferentes etapas de la integración lo brinda, como hemos dicho, la Unión Europea (UE), aún con sus dificultades. Sin embargo, es necesario realizar algunas observaciones puntuales.

La primera, como ya lo hemos destacado anteriormente, es que los acuerdos de integración por lo general no surgen desde cero, sino que se nutren de acuerdos comerciales preferenciales que han realizado entre sí los Países Miembros antes de iniciar los mencionados acuerdos de integración.

Por ello, hemos agregado una Etapa Preliminar que incluye estos esfuerzos pioneros. Es claro que es más fácil avanzar hacia una Zona de Libre Comercio (o su versión jurídica, conocida como Tratado de Libre Comercio-TLC) cuando los países involucrados ya tienen entre sí acuerdos de desgravación arancelaria; entonces el objetivo del TLC será ponerse de acuerdo 
en que tiempo y de que modos se alcanzará la desgravación total, es decir, el arancel cero para todo el universo arancelario.

Como ya hemos dicho, ayuda mucho al avance de la integración, principalmente en las primeras etapas, el tamaño y calidad del comercio "intra-bloque" con relación al comercio total que hacen los países miembros con el resto del mundo.

Así, por ejemplo, no es casualidad que la Unión Europea (UE) tenga un avance tan significativo en su proceso de integración y que su comercio intrarregional sea cercano al 70 por ciento del comercio total que esos países hacen con el resto del mundo; el NAFTA tiene también un comercio intra-bloque cercano al 60 por ciento de su comercio internacional total; y, los países asiáticos más del 35 por ciento. En contraposición, el comercio intra-latinoamericano no supera el 20 por ciento del total y el comercio intra-andino no supera el 10 por ciento del total. Rosales (2007).

No obstante, su aún pequeña participación en el comercio total de América Latina, el comercio intra-bloque de la Región es positivo debido a que favorece la diversificación de la oferta exportable en particular para las pequeñas y medianas empresas exportadoras y también promueve un mayor valor agregado en la exportación.

Por otra parte, queda claro también que se puede avanzar simultáneamente en varias de las etapas sugeridas, pero de ninguna manera obviar o "saltarse" alguna de ellas. Por ejemplo, la integración andina empezó a fines de los años sesenta con unos objetivos y programas muy ambiciosos que se enfocaron rápidamente hacia la creación de instituciones que ya correspondían a la cuarta o quinta etapa de la integración; sin embargo, en nuestra opinión, se descuidó el avance en las dos primeras etapas referidas fundamentalmente a la integración comercial.

Como resultado de ello, la Comunidad Andina (CAN) se demoró más de treinta años en lograr consolidar su Zona de Libre Comercio y hasta la fecha no ha podido concluir con la Unión Aduanera, lo que limita mucho el avance efectivo de la integración.
Sin embargo, funcionan instituciones muy eficientes como la Universidad Andina Simón Bolívar o el Convenio Hipólito Unanue sobre temas de salud (propias de la etapa del Mercado Común) o el Fondo Latinoamericano de Reservas (FLAR) o la Corporación Andina de Fomento (CAF) (instituciones que corresponden más bien a una etapa de Unión Económica) o los ciudadanos de las Países Miembros pueden viajar dentro del bloque sólo con la presentación de su documento de identidad nacional, lo que es característica del Mercado Común.

Otro ejemplo de estos "avances adelantados" lo tenemos en la ALADI que, como hemos dicho, se ubica en la Etapa Preliminar, pero, sin embargo tiene funcionando desde hace varios años el denominado Convenio de Pagos y Créditos Recíprocos (CCR-ALADI) ${ }^{6}$ que permite a los países de la Región realizar operaciones comerciales entre sí con el menor uso efectivo de divisas, al poder sus Bancos Centrales efectuar períodos de compensación cada cuatro meses, lo que se constituye en un eficaz mecanismo financiero de promoción del comercio intrarregional.

Como observamos por los ejemplos comentados, aún en los procesos de integración que se encuentran en las primeras etapas, hay valiosas experiencias institucionales y acuerdos que corresponderían a etapas más complejas pero que funcionan eficazmente y se deben ponderar.

De otro lado, también existen experiencias de integración que intentaron, desde el principio, sustentarse en una integración política y en una división del trabajo dirigida por el Estado planificador. Es el caso del denominado Consejo de Ayuda Mutua Económica (conocido por sus siglas en español como CAME o por sus siglas

6 El Convenio de Pagos y Créditos Recíprocos de la ALADI opera desde 1966 y es un importante mecanismo de integración regional, que ha ampliado progresivamente las relaciones de corresponsalía dentro del sistema bancario de la Región, produciendo ahorros sustanciales en el uso de divisas y estableciendo fuertes vínculos de cooperación entre los Bancos Centrales de los Países Miembros. Está suscrito por doce Bancos Centrales de la Región, a través del cual se cursan y compensan entre ellos, durante períodos de cuatro meses, los pagos derivados del comercio de los Países Miembros, de modo que al final de cada cuatrimestre (período de compensación) sólo se transfiere o recibe, según resulte deficitario o superavitario, el saldo global del Banco Central de cada país con el resto. El Banco Central de Reserva del Perú actúa como "Banco Agente" del Sistema y efectúa la compensación multilateral, mientras que el Federal Reserve of New York es el "corresponsal común" y procede a liquidar los saldos deudores y acreedores. 
en inglés COMECON) liderado por la entonces Unión de Repúblicas Socialistas Soviéticas (URSS) que fue creado en 1949 en el contexto de la política de economía planificada que propiciaban los denominados países socialistas.

El CAME lo integraron once países: Bulgaria, Checoslovaquia, Hungría, Polonia, Rumanía, la Unión Soviética, la entonces Alemania Oriental, Mongolia, Cuba, Vietnam y Yugoslavia. En 1989, como ya señalamos, con la caída del Muro de Berlín, el Glasnost y la Perestroika, colapsó el sistema de asignación de recursos basado en las denominadas economías centralmente planificadas.

El CAME se disolvió en 1991 y muchos de los países que lo integraron hoy ya no existen como tales. ${ }^{7}$ Pero, lo más importante, es que quedó demostrado que no basta la intención política para lograr avanzar en la integración; se tienen que dar condiciones concretas de avance por parte de los propios agentes económicos y ciudadanos en libre decisión. Sobre este último punto profundizaremos más adelante.

Por otro lado, recordamos lo que planteamos en nuestra definición de "integración" que presentamos al inicio de este ensayo, en el sentido que debemos ser conscientes, desde el principio de las negociaciones de un acuerdo de integración, que conforme se avance en las diferentes etapas, es decir, conforme se profundice el proceso, los gobiernos nacionales van perdiendo "grados de libertad" o "margen de maniobra" para aplicar sus políticas públicas en cada país.

En otras palabras, a mayor integración, debemos estar preparados para perder soberanía nacional a cambio de un beneficio mayor para el bloque regional y los propios ciudadanos.

\section{Como señala Schettino:}

“¿Cuáles son las desventajas de las asociaciones económicas? En general, éstas están asociadas a la reducción de fle-

\footnotetext{
7 La entonces Unión Soviética se disolvió y varios de los países que la integraban hoy son 15 repúblicas independientes que conforman -desde 1991- la denominada Comunidad de estados Independientes (CEI), siempre cercanas políticamente a Rusia. Alemania se reunificó (y se unieron las entonces denominadas Alemania Oriental y Alemania Occidental), Checoslovaquia se dividió en dos países: la República Checa y Eslovaquia; y, la entonces Yugoslavia se dividió, entre 1991 y 2006, en seis nuevos países: Eslovenia, Croacia, Bosnia-Herzegovina, Montenegro, Macedonia y Serbia.
}

xibilidad en la conducción de la política económica, por parte de los Países Miembros. Mientras más distorsiones se eliminan en el comercio, menos libertad tiene el gobierno de un país para determinar su política económica". Schettino (1996, p. 103).

Agregamos a lo dicho por Schettino que no sólo se trata de "menos flexibilidad" en la conducción de la política económica, sino de menores grados de libertad en todos los aspectos de la política pública, que incluye -por ejemplotemas de legislación laboral, cuidado del medio ambiente, tratamiento y protección de las inversiones, derechos humanos, y protección de la propiedad intelectual, entre otros.

El propio hecho que el Reino Unido, como integrante de la Unión Europea y mucho antes del BREXIT, nunca se integrara a la Zona Euro (es decir, mantuvo su moneda nacional -la libra esterlina- y la independencia del Banco de Inglaterra $)^{8}$ y tampoco formara parte del Acuerdo de Schengen sobre tratamiento migratorio común (y haya mantenido siempre su autonomía en la emisión de visas para extranjeros), es una muestra de cómo a veces es difícil para un país aceptar que para avanzar en la integración deba perder soberanía nacional.

Rojas Villanueva (2013) recuerda que muchos autores hablan del proceso de integración como un paso intermedio entre el "Estado-Nación” y el proceso de globalización. Dice el autor:

“...los procesos de integración tienen un punto común: la tendencia a la superación del carácter nacional del mercado y de su regulación. Ello está provocando que el ámbito Estado-Nación vaya siendo sustituido paulatinamente por la tendencia hacia la creación de formas de Estado (en el sentido de regulación económica) supranacionales". Rojas (2013, p. 46).

En la Tabla 7 podemos observar algunas de las principales consecuencias que tiene el

8 Para el Reino Unido (UK) no era aceptable perder el manejo de su política monetaria en el Banco de Inglaterra (el primer Banco Central que se creó en el mundo) a cambio de un asiento en el Banco Central Europeo (BCE) donde tendría que tomar las decisiones con un solo voto tan igual que el que tiene cada uno de los otros países miembros de la Unión Europea (UE). 
Tabla 7

El Impacto de los Procesos de Integración en las Políticas Nacionales

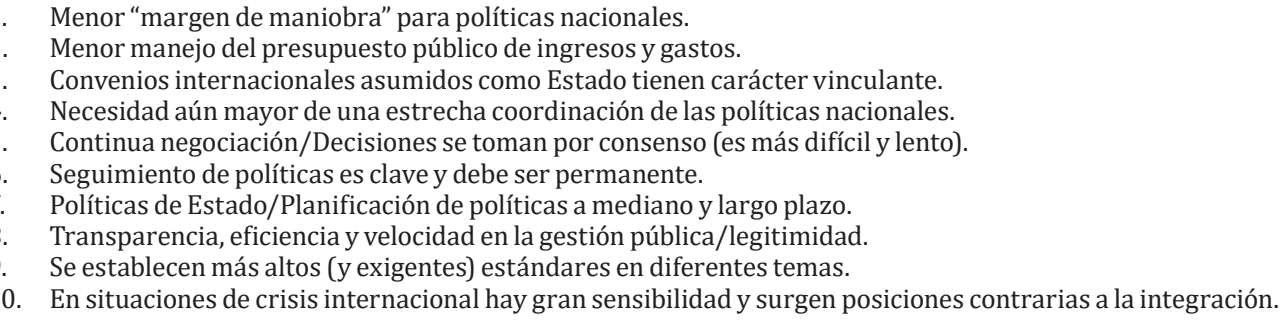

Nota: Elaborado por el autor

avance de los procesos de integración en las políticas nacionales.

\section{Como señala Stiglitz:}

"Los acuerdos comerciales significan que un país renuncia a determinados derechos; un acuerdo de libre comercio implica que el país renuncia al derecho a imponer aranceles. Sin embargo, se trata de una medida recíproca: el otro país hace algo similar. Gracias a esta reciprocidad, las ventajas de ésta ligera pérdida de soberanía pueden ser mayores que los costes". Stiglitz (2018, p. 69).

En adición al menor "margen de maniobra" de las políticas nacionales que ya hemos comentado, el avance en los procesos de integración resta también capacidad de acción a los gobiernos nacionales para el manejo del presupuesto público, el principal instrumento de política pública de un gobierno.

Esto sucede no sólo porque las decisiones van tomando, cada vez más, un carácter supranacional, sino porque parte importante del presupuesto (de ingresos y gastos) se aprueba en los Parlamentos Regionales y ya no a nivel nacional, lo que implica la necesidad de establecer otros mecanismos de negociación y de balance de poderes a fin de impulsar las iniciativas legales que se consideren convenientes. A mayor avance en el proceso de la integración, el rol de los Parlamentos Regionales va también incrementando el alcance de sus acciones y su importancia.

Por ejemplo, en la Unión Europea (UE) la discusión y aprobación de leyes sobre temas sustantivos del desarrollo de los países miembros se hace en el marco del Parlamento Europeo, cuyos integrantes son elegidos por el voto popular, pero muchas veces la composición de este Parlamento se diferencia sustantivamente de la correspondiente composición de los Parlamentos nacionales.

Por ejemplo, en el año 2019, las elecciones al Parlamento Europeo llevaron a elegir una buena cantidad de eurodiputados pertenecientes a partidos de ultraderecha y ambientalistas, quienes no necesariamente tenían esa misma representatividad en sus respectivos parlamentos nacionales. Entonces se tienen que abrir nuevos canales de diálogo y negociación para avanzar en las políticas comunitarias, pero en estrecha coordinación con las políticas nacionales.

La suscripción (multilateral o regional) de más convenios o tratados internacionales de carácter vinculante en los diferentes países hace más difícil aún el manejo de las políticas públicas en los países miembros pues muy poco es lo que se puede hacer cuando ya se han asumido compromisos de Estado en diferentes temas como la legislación laboral, el cuidado del medio ambiente o los derechos humanos.

De otro lado, si la coordinación de las políticas públicas es clave en el ámbito de los países miembros, lo es también y con mayor dificultad en el ámbito de la integración. Se hace necesario una gran dosis de flexibilidad y tener muy claros los objetivos a largo plazo para poder coordinar con éxito y no entrar en políticas que pueden tener contradicción entre sí.

Lo anterior también supone una disposición permanente al diálogo, a la negociación basada en los intereses comunes del bloque regional, lo 
que se complica aún más porque las decisiones al interior del bloque se suelen tomar por consenso. Las decisiones por consenso toman más tiempo, aunque son más estables precisamente por la unanimidad de su origen.

En nuestra opinión, tanto para las políticas nacionales como para las regionales, hay una palabra mágica que tiene que ver con los resultados que se alcanzarán: el continuo seguimiento de las mismas, a fin de garantizar el logro de los objetivos buscados en los tiempos necesarios.

Esto implica, asimismo, la necesidad de una planificación estratégica a mediano y largo plazo y de una gestión pública que deberá buscar simultáneamente la transparencia, la eficiencia y la velocidad, lo que en el corto plazo es muy difícil de lograr e incluso estos objetivos se suelen considerar como opuestos o conflictivos. Pero son necesarios para que las políticas públicas ganen legitimidad ante la población.

La mayor inserción internacional de los países y su participación en diferentes bloques regionales y de integración implica también que se van asumiendo (por "contagio", estímulo o por obligación) estándares cada vez más altos y exigentes en diferentes temas, sanitarios, ambientales, seguridad, calidad, etc.

En algunos casos, participar en bloques regionales de integración puede obedecer a políticas estratégicas de algunos países para no perder su hegemonía o su influencia en otros países, o para evitar que otras potencias interfieran en sus naturales "áreas de influencia".

Así, por ejemplo, es indudable que la participación de Alemania o Francia en la Unión Europea se debe, además de los objetivos ya comentados, al deseo de mantener una Europa unida, y a que se puedan coordinar políticas que eviten que países como Grecia, Turquía, Bulgaria o Estonia tengan situaciones de crisis financiera que podrían afectar a toda la Región y, consecuentemente, a Alemania y Francia también.

Por otro lado, no es ninguna novedad que el interés que hoy muestran los Estados Unidos. por negociar acuerdos de integración o tratados de libre comercio con diferentes países -interés que no era manifiesto algunas décadas atrásobedece asimismo a un enfoque estratégico y está incluido en su estrategia de seguridad nacional (NSS, por sus siglas en inglés). ${ }^{9}$

En la estrategia de seguridad nacional elaborada durante el gobierno del presidente Obama en 2010, aun cuando no hay una mención explícita a acuerdos regionales de integración, se reconoce que:

\begin{abstract}
“Ninguna nación, por poderosa que sea, puede enfrentar por sí misma y sin la cooperación de otros, la magnitud y complejidad de los problemas que hoy se enfrentan". Yopo (2010, p.2).
\end{abstract}

En el mismo documento hay un reconocimiento explícito al fracaso de las denominadas "estrategias unilaterales" que han estado presente en épocas anteriores en la política exterior norteamericana y el planteamiento de

“...una nueva estrategia internacional más orientada al compromiso y la búsqueda de acuerdos, y, en definitiva, a un mayor realismo respecto a las capacidades de Estados Unidos para transformar el mundo del Siglo XXI" Yopo (2010, p. 2).

Posteriormente, en la correspondiente estrategia de seguridad del presidente Trump de 2017 se habla de "promover la prosperidad estadounidense" y se ha planteado la renegociación del NAFTA y el retiro de los EE.UU. del TPP, pero sectores como el automotriz y el agrícola, y los 5 millones de puestos de trabajo en EE.UU. que dependen del NAFTA empezaron a ejercer "presión" hacia su Congreso y su Gobierno para que se mediaticen los discursos radicales del presidente Trump.

Es decir, aún en el contexto de un discurso aparentemente beligerante contra algunos acuerdos de integración firmados por los Estados Unidos, este país no puede, en las actuales circunstancias, darse el lujo de pretender actuar sólo.

9 La estrategia de seguridad nacional (NSS) es un documento preparado periódicamente por la rama ejecutiva del gobierno de los Estados Unidos para el Congreso y describe las principales preocupaciones de seguridad nacional de los Estados Unidos y la forma en que la administración planea ocuparse de ellas. Así, el presidente Obama emitió su estrategia al respecto el 26 de mayo de 2010, mientras que el presidente Trump lo hizo el 18 de diciembre de 2017. 
Es necesario señalar, además, que, cuando hay situaciones de crisis económica internacional o nos encontramos en la fase depresiva del ciclo económico (que ocurre cada cierto tiempo), frente a los problemas y restricciones presupuestarias que generalmente suceden en este contexto, resurgen sectores de la población con posiciones nacionalistas, proteccionistas o incluso con posiciones xenófobas, racistas o discriminatorias que, entre otros argumentos, señalan que la causa del problema es precisamente la participación del país en el proceso de integración y plantean la salida de los respectivos procesos o el retroceso en ciertos acuerdos de integración.

Estas reacciones que pueden ser entendidas en el contexto de las dificultades y situaciones de crisis económica, no deben sin embargo hacernos perder la brújula y los objetivos de la integración porque -en nuestra opinión- no cabe duda de que, a largo plazo, la integración será siempre importante para avanzar en el proceso de desarrollo.

En la Tabla 8 presentamos, a manera de síntesis, algunas de las reflexiones (antes anotadas) que brinda la experiencia de los países sobre el desarrollo de las diferentes etapas de la integración.

Como hemos señalado anteriormente:

“...las etapas o formas de integración deben alcanzarse gradualmente en un proceso que no está libre de dificultades porque, cuanta más integración se vaya logrando, mayor soberanía cederán los Países Miembros en beneficio del bloque y esto muchas veces es difícil de aceptar por sectores nacionalistas o instituciones que desean mantener su poder en los diferentes Países Miembros. La experiencia europea nos muestra, sin embargo, que se puede avanzar a pesar de las dificultades y que, en los tiempos actuales, hay una mayor conciencia en los países acerca de las ventajas de la integración para el proceso de desarrollo y el bienestar mundiales." Cornejo (2010, p. 240).

Como señalamos en el cuadro, se puede avanzar simultáneamente en varias de las etapas sugeridas, pero de ninguna manera obviar alguna de ellas. No estamos de acuerdo entonces con quienes hoy critican las cinco etapas planteadas inicialmente por Balassa por el hecho de que, en diferentes experiencias de bloques de integración, como ya hemos anotado en este ensayo, se observa que en algunos casos algunos bloques han dado fuerza primero a la integración política antes que a otros temas (ASEAN); otros bloques han avanzado en materias que corresponden al mercado común sin haber perfeccionado la Unión Aduanera (como el NAFTA, el MERCOSUR o la propia Comunidad Andina).

A quienes realizan esas críticas les decimos que Balassa nunca pretendió que las cinco etapas propuestas se hagan obligatoriamente siguiendo esa secuencia, incluso él ya podría haber observado en algunas de las experiencias de integración por los años sesenta que se habían obtenido logros de etapas superiores, avanzado simultáneamente en algunas de ellas

\section{Tabla 8}

Algunas reflexiones que brinda la experiencia en el desarrollo de las etapas de la integración

La integración no empieza de cero; hay acuerdos previos que otorgan preferencias arancelarias entre algunos de los países miembros. Es más fácil y más rápido avanzar hacia la consolidación de una Zona de Libre Comercio cuando ya existen acuerdos previos de preferencias arancelarias.

Se puede avanzar simultáneamente en varias de las etapas sugeridas, pero de ninguna manera obviar alguna de ellas.

Las primeras etapas de la integración son fundamentalmente referidas al comercio; a partir del mercado común la integración se profundiza con una concepción más integral del desarrollo.

El avance en las diferentes etapas de la integración depende más de condiciones concretas que se den como consecuencia de las decisiones que adopten agentes económicos y ciudadanos de cada país, antes que sólo de decisiones políticas.

Es necesario ser conscientes, desde el principio, que conforme se avance en el proceso de integración, los gobiernos nacionales perderán grados de libertad en el manejo de sus políticas públicas.

En situaciones de crisis económica internacional o de caída del ciclo económico, resurgen en los países movimientos nacionalistas o proteccionistas que consideran que la integración es la causa de los problemas.

Nota: Elaborado por el autor 
o incluso que algunos bloques se habían "saltado etapas".

Pero, aun cuando se empiece por una o por otra etapa, o se obtengan eventuales avances que corresponden a etapas más complejas, lo que queda claro es que todas las etapas deberán completarse para lograr una integración real y definitiva.

Más adelante, mostraremos un replanteamiento que propongo acerca de la división de las etapas de la integración, incluyendo la participación ciudadana.

Los diferentes acuerdos de integración vigentes nos muestran que las etapas planteadas son válidas, pero queda claro también que cada experiencia de integración debe tratarse como un caso específico, de manera que la velocidad, impulso político y resultados alcanzados dependerán de muchos factores que no necesariamente se van a repetir en otros casos.

Por ejemplo, Europa presenta condiciones de avance muy concretos en materia de integración en una región que se ha caracterizado históricamente por la división de territorios y las guerras, con diferentes Estados miembros que tienen idiomas y costumbres diferentes.

De otro lado, América Latina que, en principio, tendría mejores condiciones para integrarse (como son idioma y costumbres comunes, proximidad territorial, historia y culturas comunes) sin embargo ha demostrado tener muchas dificultades para lograr una integración regional.

Ya lo advertía hace más de doscientos años el libertador Simón Bolívar (1815) en la famosa "Carta de Jamaica"10 refiriéndose a América Latina como el "Nuevo Mundo", cuando señala:

"Y es una idea grandiosa pretender formar de todo el nuevo mundo, una sola nación con un sólo vínculo que ligue sus partes entre sí y con el todo. Ya que tiene un origen, una lengua, unas costumbres

10 Se denomina la "Carta de Jamaica" al texto que escribió el libertador Simón Bolívar, cuando se encontraba en Jamaica, como respuesta a una carta que le había enviado un comerciante británico que vivía en la isla de nombre Henry Cullen. El manuscrito con el texto completo de la carta, que fue escrita en 1815, fue encontrado en Ecuador en 1996. Este documento es valioso porque recoge el pensamiento político de Bolívar principalmente respecto al futuro de América Latina luego del proceso de independencia de España. y una religión, debería por consiguiente tener un sólo Gobierno, que confederase los diferentes estados que hayan de formarse". Bolívar (1996, p. 16).

En otra parte del mismo documento, Bolívar afirma: "Yo deseo más que otro alguno ver formar en América la más grande nación del mundo, menos por su extensión y riquezas, que por su libertad y gloria". Bolívar (1996, p. 13).

Pero el mismo Bolívar se daba cuenta de lo difícil que era poner en práctica este ideal integracionista (y lo decía a principios del Siglo XIX): “...más no es posible, porque climas remotos, situaciones diversas, intereses opuestos, caracteres de semejantes dividen a la América". Bolívar (1996, p. 16).

Con todas las dificultades que se han dado y que se seguirán dando en el futuro es nuestro convencimiento que la integración sigue y seguirá siendo una opción, camino al desarrollo, que los países deben tomar para lograr el bienestar de su población con mayor prontitud y sostenibilidad.

\section{Las nuevas teorías de la Integración}

Vivimos en un mundo globalizado y competitivo, en el que las nuevas tecnologías producen continuos cambios en nuestra vida cotidiana que nos asombran cada vez más y este contexto también han producido cambios en los acuerdos de integración en diferentes regiones del mundo.

\section{Señala al respecto García-Sordó (2007):}

"A partir de la década del ochenta, pero fundamentalmente en la siguiente, el comercio sufrió una nueva evolución. Quedó atrás el modelo de sustitución de importaciones resultado de la gran depresión y la amenaza estadounidense, y diferentes mercados se reabrieron al mercado internacional. Los países llevaron a cabo alianzas para asegurar sus intercambios comerciales y garantizar tratos preferenciales con el propósito de evitar los errores del pasado. Como consecuencia de ese proceso se formaron numerosos organismos internacionales encargados de regular las transacciones y se crearon diversos bloques 
comerciales y regionales, como el TLC y la Unión Europea. Además, se multiplicaron los acuerdos bilaterales. El aislacionismo quedó atrás y surgió fuerte y vigorosa la etapa de la integración". García- Sordó (2007, p. 51).

En nuestro libro titulado "Globalización y Comercio Internacional" (2012) señalamos:

"El nuevo proceso de globalización es totalizante y significa que lo que ocurre hoy "aquí" -por más insignificante que pueda parecer- tiene una incidencia importante "allá". Todos estamos involucrados en este proceso de permanente cambio y, muchas veces, el hecho que seamos parte del fenómeno nos impide observarlo y comprenderlo con la distancia y la objetividad que sería necesaria". Cornejo (2012, p.14). ${ }^{11}$

En un libro posterior -también de nuestra autoría- titulado "El paso siguiente de la Globalización" (2017) agregamos:

"Existe consenso con relación a que la globalización es una realidad -más allá de nuestra propia visión del fenómenoy que tiene un carácter ambivalente. De un lado tiene aspectos positivos como los derivados del impacto de las tecnologías de la información y la comunicación, la disminución de las barreras de acceso al comercio internacional, el movimiento internacional de capitales productivos o el avance de varios procesos o bloques regionales de integración. De otro lado, tiene aspectos negativos como el movimiento internacional de capitales especulativos, el crecimiento inaceptable de la brecha entre ricos y pobres...y la profundización de problemas como el deterioro del medio ambiente, las corrientes migratorias...o la globalización del terrorismo y las amenazas cibernéticas". Cornejo (2017, p. 22) ${ }^{12}$.

11 CORNEJO RAMÍREZ, Enrique...; “Globalización y Comercio Internacional”; Fondo Editorial de la Universidad Peruana Simón Bolívar (UPSB); Lima, mayo de 2012; Página 14.

12 CORNEJO RAMÍREZ, Enrique...; “El paso siguiente de la Globalización"; Fondo Editorial de la Universidad Peruana Simón Bolívar (UPSB); Lima, noviembre de 2017; Primera Edición; Página 22.
Como se aprecia, destacamos entre las consecuencias positivas de la globalización, el surgimiento o fortalecimiento de los procesos de integración regional, también conocidos como bloques regionales de integración. Son varios los factores que facilitan este proceso (Véase: Tabla 9).

\section{Tabla 9}

Algunos aspectos de la globalización que facilitan la integración entre países
- Disminuyen sensiblemente las barreras arancelarias y no arancelarias para el libre flujo del comercio internacional.
- Las nuevas tecnologías, y principalmente las tecnologías de la información y de la comunicación, permiten continua- mente reducir los tiempos y los costos de las transacciones.
- Las distancias geográficas han perdido importancia relativa por la "virtualidad" que permiten las nuevas tecnologías.
- Se relativiza la importancia de las "fronteras o demarcacio- nes territoriales" entre países.
- Los acuerdos multilaterales (por ejemplo, tipo GATT'94 o el Acuerdo Mundial sobre Medio Ambiente) llevan a los Estados Nacionales a compromisos de carácter vinculante.
- Los acuerdos se hacen simultáneamente en los ámbi- tos bilaterales, multilaterales y regionales y sobre una diversidad de temas y no sólo relacionados al comercio internacional.
- $\quad$ Abundan los denominados tratados bilaterales de libre comercio, en cuyo contenido se incluyen diversos temas de acercamiento entre países.

Nota: Elaborado por el autor

Pero, como era de esperar, estos cambios también han modificado los paradigmas de referencia. Es así que, en el actual escenario global, también están teniendo importantes modificaciones el marco teórico en el que se sustenta la integración y las propias experiencias de integración regional.

Sostenemos que uno de los cambios más destacados consiste en que actualmente los países plantean la integración con una visión "hacia el mundo", es decir, algunos países se juntan en un bloque regional pero no para "aislarse" del mundo sino para "integrarse de manera más adecuada al mundo".

Por ello, no debe extrañar que, gobiernos como los de Estados Unidos, que por décadas han promovido sólo el multilateralismo y considerado a la integración como un camino inadecuado, hoy promuevan -aunque con matices durante el gobierno de Trump- la negociación y celebración de acuerdos de libre comercio con diversos países y bloques regionales del mundo. 
Enrique García (1997), presidente ejecutivo de la Corporación Andina de Fomento (CAF) señala al respecto:

“...la integración es un proceso irreversible y urgente para que cada nación acelere el logro de su desarrollo sostenible y se inserte en forma más competitiva en el nuevo orden económico que rige actualmente al mundo". García (1997, p. i)

García, refiriéndose a la experiencia de integración en América Latina antes de los años noventa del Siglo XX, señala que:

“...hoy ningún país puede sustraerse a la realidad de la globalización ni ignorar los profundos impactos que ésta produce... Y es un hecho también que la integración es un proceso lento, difícil y complejo, que demanda respuestas innovadoras y consensos para lograr su gobernabilidad...". García (1997, p. i).

La integración, dice el autor, debe lograr sus objetivos sin vulnerar la democracia ni los principios éticos y preservando el equilibrio ecológico, para lograr así una sostenibilidad de largo plazo.

En el marco de la actual globalización, García sostiene que la integración tiene una nueva dimensión conceptual y espacial y se encamina por nuevos rumbos.

"Cuenta con actores, temas e instrumentos muy diferentes a los del pasado, con mayor flexibilidad y, lo más importante, con apoyo político al más alto nivel para contribuir a dar soluciones de corto, mediano y largo plazo... hoy la integración es un buen negocio para todos los protagonistas del proceso". García (1997, p. ii).

\section{El Nuevo Regionalismo}

Se habla de un "Nuevo Regionalismo" como alternativo al "Viejo Regionalismo" que plantearon los autores clásicos ya comentados y que enfatizaba en los aspectos comerciales, incluso considerando a la integración como una "segunda opción".
El llamado "Nuevo Regionalismo" o la nueva forma de entender la integración considera entonces que avanzar en el campo de la integración no es contradictorio con el esfuerzo multilateral de libre comercio.

Por ello, en el nuevo acuerdo del GATT de 1994 que aplica la Organización Mundial del Comercio $(\mathrm{OMC})^{13}$ también se permite que los Países Miembros celebren acuerdos de integración o tratados de libre comercio (TLC's) pero a condición de que los países participantes, aceleren su proceso de desgravación arancelaria y no retrocedan en su proceso de apertura al comercio mundial ${ }^{14}$.

El Acuerdo GATT 199415, en su artículo XXIV, sobre aplicación territorial, tráfico fronterizo, uniones aduaneras y zona de libre comercio señala claramente:

"Las partes contratantes reconocen la
conveniencia de aumentar la libertad
del comercio, desarrollando, mediante
acuerdos libremente concertados, una
integración mayor de las economías de
los países que participen en tales acuer-
dos. Reconocen también que el estable-
cimiento de una unión aduanera o de
una zona de libre comercio debe tener

13 El GATTT corresponde a las siglas en inglés de General Agreement on Tariffs and Trade ó Acuerdo General sobre Aranceles Aduaneros y Comercio. El primer GATT se firmó en Ginebra en 1947 como parte de los esfuerzos multilaterales para reconstruir la economía mundial después de la guerra. El nuevo Acuerdo GATT, firmado en 1994 en Marrakech-Marruecos y dio origen a la Organización Mundial de Comercio (OMC) que inició sus actividades en 1995.

14 El artículo XXIV del GATT (1994) establece la posibilidad de constituir zonas de libre comercio, abiertas a terceros países y reconoce la compatibilidad de un tratado que instaura un bloque económico comercial con el acuerdo general de libre comercio bajo tres condiciones: a) que la creación del área económica integrada se realice en un período de tiempo razonable; b) que los derechos aduaneros respecto de terceros países no suban en relación a los que se aplican en los países miembros antes de la integración; y c) que las otras disposiciones comerciales a aplicar en el área integrada no sean más rígidas de las vigentes en los países miembros.

15 El Acuerdo GATT 1994 se refiere al "Acuerdo General sobre Aranceles Aduaneros y Comercio de 1994". Este instrumento, denominado "GATT de 1994", se basa en el texto del Acuerdo General sobre Aranceles Aduaneros y Comercio original, denominado "GATT de 1947". El GATT de 1994 se firmó en Marrakech-Marruecos en marzo de 1994 luego de una negociación de más de siete años en lo que se denominó la "Ronda Uruguay" entre 1986 y 1993. La denominación GATT corresponde a las siglas en inglés: "General Agreement on Tariffs and Trade". La Organización Mundial de Comercio (OMC), creada en el marco del GATT de 1994, inició sus actividades el 01 de enero de 1995. 
por objeto facilitar el comercio entre los territorios constitutivos y no erigir obstáculos al de otras partes contratantes con estos territorios.

Por consiguiente, las disposiciones del presente Acuerdo no impedirán, entre los territorios de las partes contratantes, el establecimiento de una unión aduanera ni el de una zona de libre comercio, así como tampoco la adopción de un acuerdo provisional necesario para el establecimiento de una unión aduanera o de una zona de libre comercio..." OMC (1994).

De acuerdo a la legislación multilateral vigente, la OMC permite a sus Países Miembros participar en bloques regionales de integración (Unión Aduanera u otro tipo de acuerdo) a condición de que se cumplan tres requisitos: a) los derechos de aduana que se establezcan en dicho bloque no tengan "una incidencia más elevada" ni tengan reglamentaciones comerciales más rigurosas a las vigentes en los países socios antes de la constitución del bloque; b) los derechos de aduana que se establezcan con terceros países no miembros del bloque no sean más elevados ni las reglamentaciones comerciales más rigurosas que las que ya existían antes de constituir el bloque regional; $y, c)$ el acuerdo respectivo a que se refieren los dos puntos anteriores incluya un programa para el establecimiento, en un plazo razonable, de una zona de libre comercio o de una unión aduanera.

Por lo tanto, desde la normatividad multilateral se permite claramente la participación de los países miembros de OMC en acuerdos regionales de integración a condición de que los acuerdos que se establezcan en el bloque apunten claramente a una mayor liberalización comercial y no al revés.

Incluso, desde esta nueva perspectiva de análisis, el multilateralismo puede ser visto como una forma de integración a la economía mundial en su conjunto y el regionalismo como una forma de integración al mundo en grupos de países denominados "bloques regionales".

Rebolledo (1993), citando a autores como De Melo y Panagariya (1992) señala:
"Todas estas definiciones, conceptos y formas de evaluación referidas a la integración (se refiere a los conceptos clásicos sobre el tema) están siendo complementadas con nuevas ideas $\mathrm{y}$ discusiones políticas que marcan el debate actual sobre el llamado Nuevo Regionalismo". Rebolledo (1993, p. 6).

Rebolledo agrega que los ingredientes nuevos incorporados al debate académico -frente a lo que se decía en las décadas del cincuenta y del sesenta- eran básicamente tres: los problemas surgidos de la Ronda Uruguay de negociación comercial en el marco del GATT que hacían ver con cierto escepticismo el sistema multilateral de comercio; la tendencia del mundo hacia un esquema en tres grandes bloques: la entonces Comunidad Económica Europea (CEE), la búsqueda de una zona de libre comercio hemisférica liderada por los EE.UU., y los esfuerzos que se observaban en Asia liderados por Japón; y, el que los nuevos esquemas de integración incorporen a países desarrollados y países en desarrollo.

Han habido otros acontecimientos mundiales de importancia en las décadas posteriores al análisis de Rebolledo, pero el "Nuevo Regionalismo", como concepto, ha seguido siendo parte de las discusiones académicas sobre la integración en un contexto de globalización.

Con respecto al "Nuevo Regionalismo" propusimos lo siguiente:

"El Nuevo Regionalismo es un proceso más generalizado, pues participan en él tanto países industrializados como países en desarrollo, países grandes y países pequeños; hay experiencias muy avanzadas como la de la Unión Europea y... no necesariamente el Regionalismo va en contra de un comercio mundial más libre". Cornejo (2010, p. 243).

De Melo y Panagariya señalaban:

"Sobre el principio mismo de la integración el profesor Paul Krugman sostuvo que los bloques comerciales son malos en principio, pero buenos en la práctica; mientras que el profesor Jagdish Bhagwati adoptó la posición inversa, diciendo que los bloques comerciales pueden 
ser buenos en principio, pero probablemente malos en la práctica". Rebolledo (1993, p. 8).

Dijimos al respecto en 1996:

"Los economistas se preguntan cuáles serían los probables efectos que el Nuevo Regionalismo producirá en el sistema comercial multilateral. Al respecto, hay diferentes opiniones, pero lo que queda claro es que esta vez el Regionalismo se ha establecido definitivamente". Cornejo (2010, pp. 243-244).

Los que plantean una posición más favorable al libre comercio, como Bhagwati, consideran que el Regionalismo tiene más escollos, es más lento y menos eficiente que el Multilateralismo y amenaza socavarlo. Los que se oponen al Regionalismo sostienen también que los bloques comerciales regionales han tenido una orientación hacia el interior de sus economías y ponen como ejemplo precisamente la estrategia de sustitución de importaciones que puso en práctica América Latina en la década del setenta y que ya mencionamos.

Se plantea, de otro lado, que el Regionalismo supone una amenaza que aleja al mundo del libre comercio, debido a la creciente tendencia a utilizar barreras no arancelarias como el medio para ajustarse a un súbito repunte de las importaciones que comercian entre sí en el marco de un Acuerdo Regional.

Se trata, para estos autores, de una especie de "nuevo proteccionismo". Los defensores del "libre comercio" buscan reducir las barreras arancelarias y no arancelarias al comercio internacional a través de negociaciones multilaterales en el marco del GATT y bajo la promoción de la Organización Mundial de Comercio (OMC).

Por su parte, otros autores son más partidarios del Regionalismo (y aquí incluimos a Krugman, aun cuando -como ya hemos vistosu visión de la integración es más como una segunda opción) y señalan que las negociaciones a favor de un comercio más libre tendrían más posibilidades de éxito si se llevaran a cabo entre grandes bloques que entre muchos países involucrados.
Los "regionalistas" también sostienen que las negociaciones comerciales regionales han ido más allá de la reducción de los aranceles en las negociaciones multilaterales, ahondando en temas como la armonización de políticas y las normas sobre productos y servicios. Se pone como ejemplo de experiencia exitosa en esta materia a la Unión Europea, señalándose precisamente que los resultados alcanzados superan los límites estrechos del aumento de la eficiencia, a través de eliminar distorsiones, y que todo ello ha contribuido a disminuir los conflictos internos.

\section{Señalamos entonces:}

"El debate no es sencillo pues, si bien la integración tiene efectivamente una serie de beneficios para los Países Miembros, supone, por definición, promover un libre comercio al interior del bloque, pero, al mismo tiempo, establecer barreras comerciales con terceros países. El "efecto neto" debe evaluarse en cada caso, pero queda claro que la concepción con la que se está trabajando actualmente en la integración está mucho más cerca de los esfuerzos multilaterales que antes". Cornejo (2010, p. 244).

Terciando en el debate, como veremos más adelante, la Comisión Económica para América Latina (CEPAL) ha planteado su nueva propuesta de "Regionalismo Abierto" en la que considera que el multilateralismo y el nuevo regionalismo avanzan en forma convergente hacia el objetivo común de lograr un mayor bienestar mundial.

Es decir, los autores parecen ponerse de acuerdo en que ambos son caminos diferentes pero que llegan a la misma meta: los países pueden desarrollar esfuerzos en solitario integrándose al mundo a través de los acuerdos multilaterales del GATT y la OMC o también pueden avanzar en grupos de países conformando bloques regionales de integración; ambos caminos orientados al desarrollo y al mayor bienestar de su población.

García-Sordó (2007) señala que el nuevo regionalismo puede definirse en términos de dos componentes: el regionalismo económico y la mentalidad regional. Según el autor, 
"El regionalismo económico se basa en el deseo de los agentes económicos y las naciones soberanas de mejorar el ámbito de bienestar de sus integrantes", mientras que la "...mentalidad regional resulta de compartir valores y creencias que dan forma a una visión de lo que quieren llegar a ser los miembros regionales". García-Sordó (1997, pp. 300-301).

García-Sordó está de acuerdo con otros autores en el sentido que el nuevo regionalismo es la consecuencia de varios factores tales como: el lento progreso del libre comercio multilateral promovido por el GATT, la proliferación de barreras no arancelarias, la fortaleza relativa que ha ido mostrando Europa en su proceso de integración y el surgimiento de nuevos Estados democráticos.

Björn Hettne (2002), investigador de la Universidad de Gotemburgo-Suecia, ha sistematizado las diferencias entre el viejo y el nuevo regionalismo. Señala Hettne que el viejo regionalismo se formó en el ámbito bipolar de la guerra fría mientras que el nuevo regionalismo ha aparecido en un orden mundial multipolar enmarcado por la globalización.

Es decir, para el autor, “...nuevo regionalismo y multipolaridad, son dos caras de la misma moneda" Hetne (2002, p. 955).

Vivimos efectivamente en un mundo multipolar, en el que han surgido -además de los Estados Unidos, la Unión Europea y Japónotros actores protagónicos de la economía y política mundial como China, India o Rusia y otros países más pequeños pero que unidos en nuevos y dinámicos bloques regionales en diversos continentes están teniendo cada vez una mayor importancia.

De otro lado, el viejo regionalismo se creó "desde arriba", mientras que el nuevo regionalismo es un proceso más voluntario en el que los países participantes sienten que deben unirse para conducirse adecuadamente en los nuevos escenarios mundiales. El viejo regionalismo era proteccionista y, como ya dijimos, se "orientaba al interior"; el nuevo regionalismo se considera abierto y compatible con una economía mundial interdependiente.
El viejo regionalismo, continúa Hettne, tenía objetivos específicos como lo económico o la seguridad; el nuevo regionalismo es esencialmente multidimensional. El viejo regionalismo sólo se ocupaba de las relaciones entre los Estados-Nación; el nuevo regionalismo opera en un contexto global en el que actúan también diversos actores no estatales.

Así, el nuevo regionalismo presenta características muy significativas, como la multipolaridad por la existencia de nuevos actores protagónicos en el escenario mundial; hay también una suerte de "realismo" o "pragmatismo" que acompaña el proceso de integración antes que la formalidad misma; una visión multidimensional en la que aparecen diversos factores y no sólo los estrictamente comerciales; y una visión "hacia afuera", mirando al mundo y, por lo tanto, aprovechando la mayor interdependencia que plantea la globalización y que exige países y economías más dispuestas a participar activamente en el escenario internacional, incluso trabajando simultáneamente en negociaciones bilaterales, regionales y multilaterales.

Hettne se refiere a lo que denomina una "historia natural de la regionalización" y define cinco etapas en la formación de la "regionalidad" enfocada en lo político, las que se muestran en la Tabla 10. Lo básico de la posición del autor es que el nuevo regionalismo debe entenderse necesariamente en el contexto de la globalización.

\section{Tabla 10}

Etapas de la Regionalidad enfocada en lo político, según Hettne

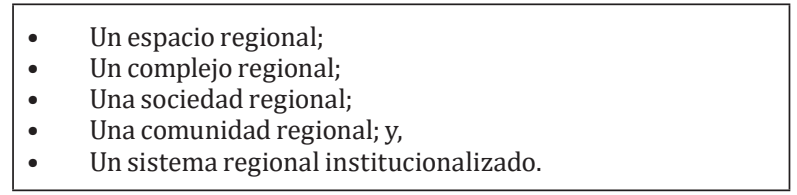

Fuente: HETTNE (2002).

El autor considera que un "espacio regional" es una zona geográfica delimitada por barreras más o menos naturales y físicas. La región tiene sus raíces en el territorio: un ejemplo es Europa, desde el Atlántico a los Urales.

De otro lado, un "complejo regional" se refiere a una permanente profundización de las relaciones entre localidades de los grupos humanos. Las partes (por lo general Estados) 
son dependientes entre ellas, así como de la estabilidad general del sistema regional. En este caso, lo que los une son los conflictos o la seguridad y se manifiesta en conquistas y ocupaciones territoriales.

Una "sociedad regional" implica, para el autor, una cooperación más organizada, pudiendo ser espontánea u organizada en los ámbitos culturales, económicos, militares o políticos. Se trata de una región formal y el patrón de las relaciones es regulado.

Por su parte, una "comunidad regional" toma forma cuando un marco organizativo durable promueve la comunicación social y la convergencia de los valores y crea así "una sociedad civil transnacional" en ámbitos económicos, políticos y de seguridad.

Finalmente, un "sistema regional institucionalizado" posee una estructura más apropiada para la toma de decisiones y una capacidad de acción más sólida. Las áreas cruciales para la intervención regional en este caso podrían ser la prevención y el manejo de catástrofes y emergencias naturales en la región; el análisis y la resolución de conflictos y la creación de un sistema de bienestar que mejore el equilibrio general

Lo interesante de este planteamiento de etapas de la regionalidad enfatizando en lo político es que evidencia que la globalización es un marco propicio para la constitución de nuevos y más dinámicos bloques regionales de integración y que el efecto de la globalización es diferente en las distintas condiciones históricas de la regionalidad y crea diferentes vías de regionalización.

Lo anterior, deberá tenerse en cuenta entonces para evaluar las diferentes experiencias de bloques regionales de integración, su contexto y posibilidades. Señala Hettne: "La autarquía regional ya no es una opción. La globalización es el desafío exógeno que provoca una respuesta regionalista" Hetnne (2002, p. 958).

El autor, citando a Polanyi (1992) señala que:

“...la globalización contemporánea se concibe...como un esfuerzo para institucionalizar el sistema de mercado en escala mundial y las tendencias a favor de la creación de formaciones regionales en todo el mundo se consideran como un intento político...de administrar la turbulencia social que conlleva la desregulación radical y sin precedente en términos de su alcance mundial". Hetnne (2002, p. 959).

Actualmente, se ha incrementado significativamente el número de acuerdos regionales en todo el mundo, al punto que podríamos afirmar que pocos son los países que no pertenecen de alguna manera (miembros plenos, asociados, observadores, etc.) a algún acuerdo regional. Pero el cambio no es sólo cuantitativo, sino también se observa en el contenido y alcances de la integración.

Por otro lado, cada uno de los acuerdos regionales tiene su propia dinámica y características peculiares, las que difieren también en función al número de sus integrantes, el punto de partida de sus negociaciones o los espacios geográficos o geoeconómicos en los que se desarrollan.

Así, podemos hablar de muchos regionalismos, con cambios cualitativos importantes frente a experiencias anteriores. Por ejemplo, en América Latina y el Caribe difieren las experiencias de la CAN y la Alianza del Pacífico, o la del MERCOSUR y el NAFTA; y también difieren las experiencias de integración en América Latina con las de Europa y de éstas con las experiencias de integración en Asia o África. Además, hay experiencias de integración intercontinentales, lo cual es una significativa novedad.

En este aspecto, René Hernández de la Universidad de Chile destaca que hay importantes cambios cualitativos en los acuerdos regionales de integración y precisa que tres son los más importantes (Véase la Tabla 11).

Hernández señala que:

"A partir de la década de los noventa se entró a una nueva fase de las relaciones económicas internacionales, caracterizada por un crecimiento acelerado de los flujos transfronterizos de bienes, servicios y capitales, dando origen a un proceso irreversible de hiperglobalización y conformación de bloques económicos 
de escala global y negociaciones mega regionales. El más sobresaliente y controvertido a la vez es el Acuerdo de Asociación Transpacífico (TPP)" Hernández (2018, pp. 149.-150).

En la Tabla. 12 presentamos las principales características que observamos en los acuerdos regionales (los antiguos repotenciados y los nuevos) en el nuevo contexto global y competitivo.

Hay pues, en las primeras décadas del Siglo XXI, un ambiente más propicio para desarrollar acuerdos regionales y lograr avances más concretos en tiempos menores.

Por ejemplo, como hemos dicho, la Comunidad Andina se demoró varias décadas en consolidar su Área de Libre Comercio, sin embargo, la Alianza del Pacífico, en unos pocos años de existencia ya prácticamente logró la liberalización del total de su universo arancelario.

¿La razón? Los cuatro países miembros de ésta última (Chile, Colombia, Perú y México) tienen mayor cercanía en las políticas macroeconómicas que aplican en sus respectivas economías nacionales y, además, el punto de partida de la correspondiente negociación fue un nivel arancelario promedio bastante bajo, pues los cuatro países ya habían negociado previamente sendos tratados de libre comercio entre sí (bilateralmente) y con los principales países y bloques del mundo.

Se trata ahora de una integración "que mira al mundo", para contrarrestarla con la integración de la segunda mitad del Siglo XX que claramente era una integración "defensiva", es decir, que los países miembros se juntaban en el grupo regional para "defenderse" de otros países y especialmente de los países más desarrollados, coexistiendo los esfuerzos de integración con políticas proteccionistas en los ámbitos nacionales.

Por ejemplo, en América Latina y el Caribe las políticas predominantes en las décadas del setenta y ochenta se orientaban dentro de la denominada "Estrategia de Sustitución de Importaciones" que auspiciaba entonces la CEPAL y que significaba, en la práctica discriminar entre importaciones (favoreciendo a las que

\section{Tabla 11}

Principales cambios cualitativos en los Acuerdos de Integración en el Nuevo Regionalismo

1. Se pasa de un modelo de regionalismo cerrado a uno más abierto (en el que hay más fomento del comercio exterior que control del mismo);

2. Se reconoce que una integración efectiva requiere no sólo la eliminación de barreras arancelarias y de cuotas, sino también de otras barreras al comercio ("integración profunda); $y$,

3. Surgen nuevos bloques comerciales en los que los países de altos ingresos y los países en desarrollo actúan como socios en pie de igualdad (Acuerdos Norte-Sur).

Fuente: HERNÁNDEZ (2018, p. 151).

\section{Tabla 12}

Principales Características de los Acuerdos Regionales en los albores del Siglo XXI

1. El Regionalismo se ha extendido en el mundo, con nuevos y dinámicos bloques regionales y el reforzamiento de otros.

2. Hoy se plantea la convergencia entre los objetivos del multilateralismo y los del regionalismo.

3. Se trata ahora de una integración que "mira hacia el mundo", dejando la "integración defensiva" del Siglo XX.

4. Los acuerdos regionales ya no se limitan a los países limítrofes; se unen por razones geoeconómicas o políticas países que están a grandes distancias entre sí (como los países integrantes de APEC).

5. Los acuerdos regionales se conforman con países de tamaño grande y pequeño.

6. Los acuerdos incluyen a socios de diferentes ideologías o creencias religiosas (por ejemplo: China un país comunista y los EE.UU. un país capitalista son socios en APEC; en varios acuerdos hay países de mayoría católica, con otros budistas o musulmanes).

7. El punto de partida para las negociaciones es mucho más propicio que antes porque hay muchos avances en la desgravación arancelaria en el marco del Acuerdo GATT'94 o de los varios TLC's vigentes.

8. La mayor interdependencia mundial producto de la globalización ayuda a avanzar más rápidamente en los acuerdos regionales.

9. Se avanza no sólo en temas comerciales, sino en aspectos específicos como la integración física, la cooperación para el desarrollo, el cuidado del medio ambiente o las políticas energéticas.

10. Los nuevos acuerdos regionales tienen modernos y eficaces mecanismos de solución de diferencias los que generan mayor transparencia y confianza.

Nota: Elaborado por el autor 
se consideraban "prioritarias") y desalentar las exportaciones.

Este tipo de "integración defensiva" también ponía regulaciones y hasta prohibiciones a la repatriación de utilidades a los países de origen de las empresas extranjeras que habían invertido en el bloque regional. Por una decisión de este tipo (la denominada Decisión 24 que limitaba al 10 por ciento la repatriación de utilidades de las empresas extranjeras), Chile decidió retirarse del entonces Grupo Andino, en los primeros años de la década del setenta.

Dietmar Dirmoser resume lo sucedido en América Latina:

"Durante mucho tiempo aumentar el grado de integración económica entre los países latinoamericanos ha sido una meta indiscutible. Se esperó que la integración dinamizara las economías reduciendo su dependencia de los mercados primarios internacionales e impulsando la industrialización. Este deseo se ha plasmado en diversos esquemas de integración subregional, que han sido golpeados en su conjunto duramente por la crisis internacional, Pero, la idea de integración no dejó de tener un gran poder de seducción: como lo demuestra el relanzamiento del GRAN en las Cumbres de Galápagos y Cartagena, así como la puesta en marcha del Mercosur y del NAFTA". Rebolledo (1993, p. 9).

Ahora nos encontramos en otro contexto, se propicia una mayor apertura e inserción de las economías nacionales en el comercio mundial y la participación en los bloques regionales cuenta incluso -como ya hemos señaladocon el beneplácito de la OMC (en el marco del GATT'94) en la medida que los países se unan en el bloque para seguir -esta vez conjuntamente- profundizando en su desgravación arancelaria y no al revés. Se busca entonces la convergencia entre objetivos y políticas regionales con las multilaterales.

Stiglitz llama la atención sobre el hecho que los acuerdos comerciales en el nuevo contexto internacional, partiendo de niveles arancelarios ya muy bajos, "...se han centrado en la regulación. Ahora, los productores de un país dicen que podrían vender más en otro, si el Gobierno eliminara alguna norma, por ejemplo, sobre emisiones, contaminantes o seguridad". Stiglitz (2018, p. 71).

El hecho que los nuevos acuerdos regionales ya no se limiten a países limítrofes es también un cambio muy importante, pues ahora existen otros factores de convergencia de intereses como pertenecer a la Cuenca del Pacífico en la APEC (que incluye países de tres continentes).

Es importante en este punto también destacar las ventajas que presentan las nuevas tecnologías de la información y de la comunicación que abrevian los tiempos y hacen menos importantes las distancias. Así, una negociación entre funcionarios de gobiernos de Perú, Australia y China puede hacerse simultáneamente vía Skype, o los ministros de Agricultura de Perú y los Estados Unidos. pueden resolver rápidamente vía una videoconferencia un problema sanitario que puede haber surgido en alguna operación comercial.

Los nuevos acuerdos regionales tienen contenidos mucho más amplios que los sólo comerciales, lo que ayuda a avanzar más rápido hacia las etapas más complejas del proceso de integración. Son acuerdos regionales con agendas más completas, con países más diversos, grandes y pequeños, industrializados y menos industrializados e incluso con países de diferentes ideologías políticas o creencias religiosas; todos son socios con objetivos e intereses comunes que apuntan al desarrollo regional y, por supuesto, al desarrollo global.

Hernández (2018) presenta un panorama de la integración regional y el Nuevo Regionalismo en América Latina y el Caribe, resaltando algunos temas emergentes en las primeras décadas del nuevo siglo como el BREXIT, la renegociación del NAFTA, el Acuerdo de Asociación Transpacífico (TPP) y la propia Alianza del Pacífico (AP).

Hernández considera los nuevos temas que están incluidos en las agendas de negociación de la integración en esto tiempos (y que van más allá del intercambio comercial) tales como la gradual coordinación macroeconómica y en políticas tan diversas como la infraestructura, la energía o el ámbito regulatorio; 
el fortalecimiento del vínculo con China y el Asia-Pacífico (lo que considera un verdadero desafío), el comercio de servicios y la integración productiva. A todos ellos los denomina "mecanismos de una integración más profunda”. Hernández (2018, pp. 149-159).

Refiriéndose a América Latina y el Caribe en el nuevo contexto, Hernández sostiene que:

"En un contexto de creciente proteccionismo, la integración regional y el Nuevo Regionalismo pueden constituirse en los pilares que impulsen y sostengan un desarrollo más inclusivo para toda la Región”. Hernández (2018, p. 150).

\section{El Regionalismo Abierto}

Hernández sostiene:

"La CEPAL contribuyó al debate sobre los procesos de integración regional con una propuesta de "Regionalismo Abierto", que combinaba los acuerdos subregionales de liberalización, con la apertura unilateral y el avance hacia la integración hemisférica". Hernández (2018, p. 151).

CEPAL define Regionalismo Abierto de la siguiente manera.
Definición de Regionalismo Abierto según CEPAL

“...proceso de creciente interdependencia económica a nivel regional, impulsado tanto por acuerdos preferenciales de integración como por otras políticas en un contexto de apertura y desreglamentación, con el objeto de aumentar la competitividad de los países de la Región y de constituir, en lo posible, un cimiento para una economía internacional más abierta y transparente".

Fuente: CEPAL (1994, p. 8).

Para CEPAL, incluso si no se produjera un escenario óptimo de convergencia como el planteado, el Regionalismo Abierto de todas maneras cumpliría una función importante para contrarrestar eventuales presiones proteccionistas en mercados extrarregionales.

En el razonamiento de CEPAL, ninguno de los países (sean desarrollados o en proceso de desarrollo) que han asumido compromisos de integración lo han hecho como una alternativa a una inserción más dinámica en la economía internacional; los han considerado más bien procesos complementarios.

En la Figura 1, presentamos esquemáticamente la propuesta de CEPAL, observándose

Figura 1

El Regionalismo Abierto en la propuesta de CEPAL

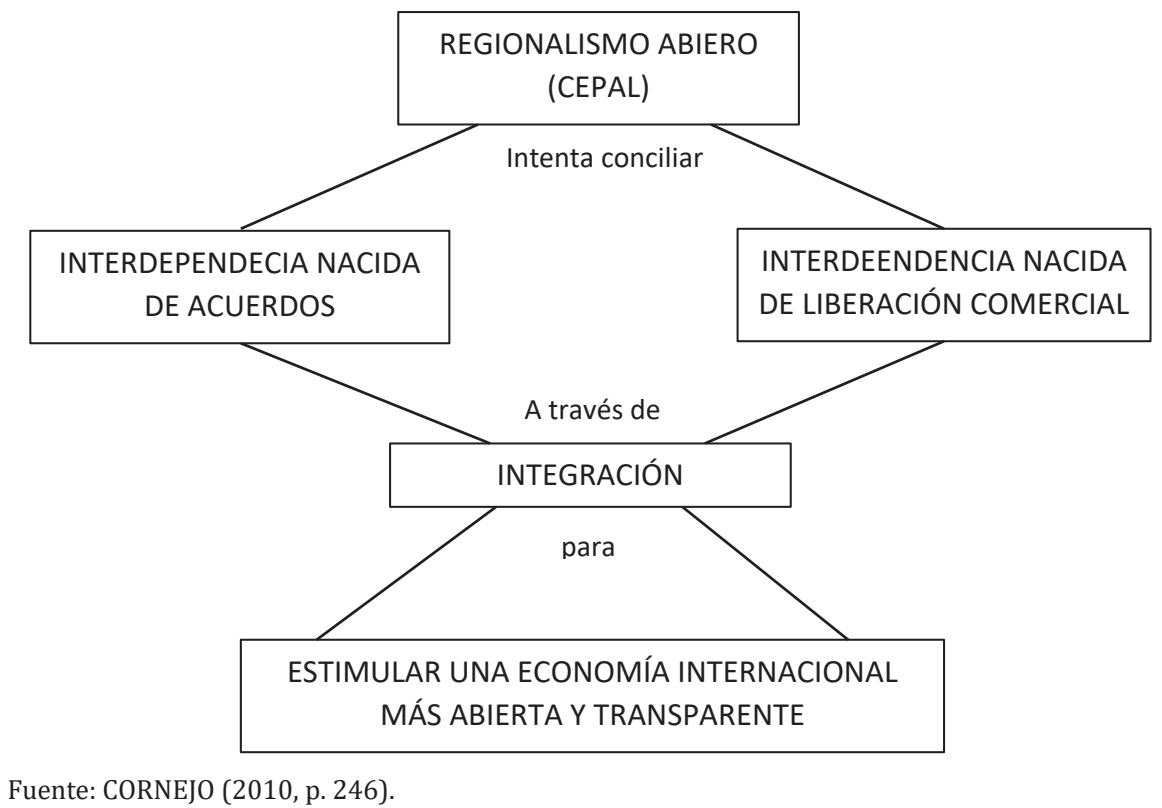


claramente que el objetivo es el mismo siempre: estimular una economía internacional más abierta y transparente para conseguir un desarrollo sostenido y un mayor bienestar de la población.

Para ello, se consideran como caminos paralelos y no contradictorios tanto la interdependencia nacida de acuerdos (regionalismo) como la interdependencia nacida de la liberación comercial (multilateralismo), y a ello se llama "Regionalismo Abierto". Se trata, en otras palabras, de esfuerzos de integración regional que apuntan a una mayor integración mundial.

La finalidad-sostiene CEPAL-

“...es la instauración de una economía internacional más abierta y transparente: los procesos de integración serían los futuros cimientos de una economía internacional libre de proteccionismo y de trabas al intercambio de bienes y servicios". CEPAL (1994, p. 11).

El organismo internacional sostiene que el ambiente que se vive en estos tiempos con respecto a la integración es muy diferente al escepticismo que se tenía en la década del ochenta. Llama la atención que ahora proliferan acuerdos de diversa índole, entre países grandes y pequeños, entre países desarrollados y en desarrollo, muy heterogéneos en cuanto a sus modalidades y configuración geográfica.

Los países latinoamericanos, en particular, suscriben numerosos acuerdos de comercio preferencial, muchos de ellos en el marco de los instrumentos que brinda ALADI como son los Acuerdos de Alcance Parcial y Acuerdos de Complementación Económica que propician el comercio intrarregional. También hay varios acuerdos destinados a formar zonas de libre comercio recíprocas, las cuales -si bien no tienen en principio el objetivo de alcanzar un mercado común- incluyen contenidos que van más allá de sólo el aspecto comercial, produciéndose por ejemplo la coordinación de políticas macroeconómicas y de migración.

Para CEPAL hay, además, “...una integración de hecho" impulsada por las políticas de los países de la Región:
"El proceso también ha avanzado "de hecho", bajo el influjo de un conjunto de políticas macroeconómicas y comerciales que, sin ser discriminatorias con respecto al comercio con terceros países, han tenido por efecto la creación de condiciones similares en un número creciente y ya mayoritario de naciones de la Región y alentando así el comercio y la inversión recíprocas". CEPAL (1994, p. 12).

Hay, definitivamente, un mayor comercio entre los propios países latinoamericanos, aunque está todavía muy bajo comparado con el comercio intra-bloque de otras regiones como Europa y Asia.

Lo que busca el "Regionalismo Abierto" es que las políticas de integración sean compatibles con las políticas destinadas a elevar la competitividad internacional y que se complementen. En este sentido, los acuerdos de integración deberían esforzarse por eliminar las barreras aplicables a la mayor parte del comercio de bienes y servicios entre los Países Miembros en el marco de sus políticas de liberalización comercial frente a terceros y, además, deberían buscar la adhesión de nuevos Países Miembros.

Entre estas tareas necesarias para promover la integración en un contexto de "Regionalismo Abierto", CEPAL considera compromisos para una disminución gradual de la discriminación intrarregional, la estabilidad macroeconómica en cada país, el establecimiento de mecanismos y facilidades de pago, la facilitación del comercio, la construcción de infraestructura y la armonización de políticas públicas y regulaciones diversas.

CEPAL incluye varias características que favorecen el "Regionalismo Abierto", las que se muestran en la Tabla 13.

Como observamos en la tabla, los doce factores que plantea CEPAL para favorecer el impulso del "Regionalismo Abierto" son factibles de lograr con voluntad política y, principalmente con Políticas de Estado que se mantengan en el tiempo no obstante que cambien los gobiernos nacionales.

En primer lugar, debe haber una voluntad de los países de avanzar en el proceso de 
Tabla 13

Principales Características que favorecen el "Regionalismo Abierto"

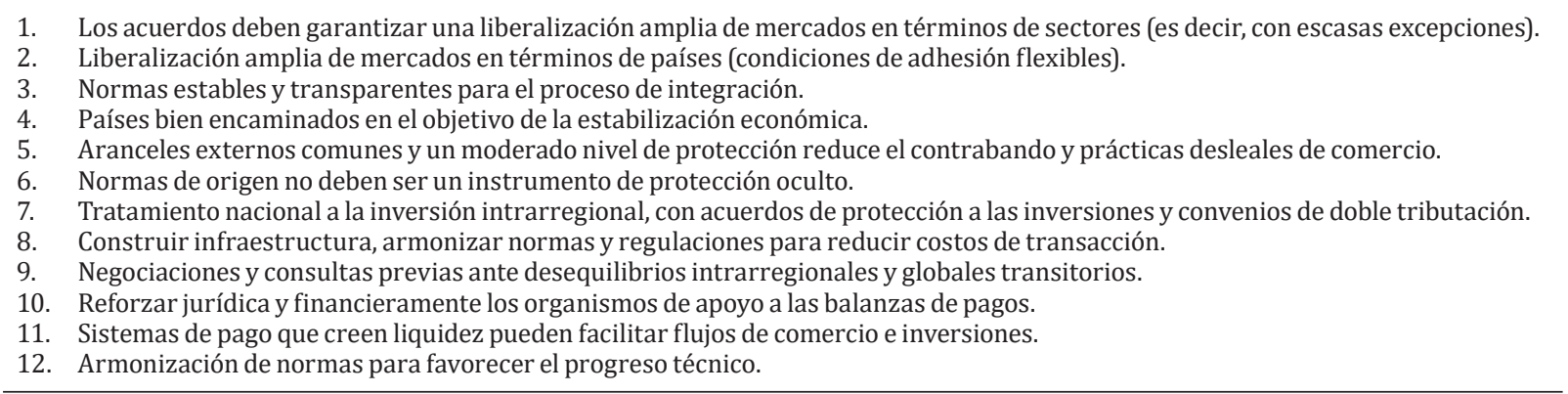

Nota: Elaborado por el autor con base en información de CEPAL.

desgravación arancelaria. Como hemos dicho anteriormente la integración de estos tiempos "mira hacia afuera" y, por lo tanto, busca en conjunto con los otros países socios avanzar en su proceso de desarrollo, con una también mayor apertura de su comercio e inversiones hacia la economía mundial en su conjunto.

De otro lado, la flexibilidad es fundamental en un proceso de integración en el que normalmente el punto de partida de negociación tiene diferencias muy importantes entre países. La incorporación de nuevos socios tiene que tener entonces facilidades que busquen la gradualidad, mayores plazos y, en algunos casos, tratamientos diferenciales acotados en el tiempo.

Se requiere predictibilidad para la toma de decisiones y, en especial para las nuevas inversiones que quieren aprovechar las ventajas del mercado ampliado. Para ello, son necesarias políticas macroeconómicas que generen estabilidad, normas y reglamentos claros y que se mantengan en el tiempo, además de normas de origen que no se utilicen como prácticas paraarancelarias, es decir, como pretextos para dificultar el libre flujo del comercio.

El tratamiento de las inversiones de los otros países socios como inversiones nacionales, con iguales posibilidades de acudir a soluciones de diferencias independientes, con acuerdos de protección de inversiones y que eviten la doble tributación, son todas condiciones muy importantes para generar confianza en los inversionistas y promover la innovación y el desarrollo tecnológico.

Es importante también tener disponibles mecanismos financieros sólidos para atenuar problemas de balanza de pagos entre países, de manera que en estas condiciones de dificultad o de crisis no se retroceda en lo avanzado en materia de los acuerdos de integración. Se debe hacer un seguimiento permanente y tener los mecanismos adecuados para actuar a tiempo frente al eventual problema.

En América Latina, a diferencia de otras regiones del mundo, el tamaño de los negocios es mayoritariamente pequeño $0^{16}$ y este es un problema que dificulta el aprovechamiento de los mercados ampliados. Hay pequeñas empresas en Europa o Asia, pero muchas veces el tamaño de éstas es el equivalente de una mediana empresa en América Latina.

Por ello, una característica adicional a las señaladas por CEPAL será necesariamente la promoción de mecanismos de asociación y capacitación para lograr que las unidades económicas empresariales superen este problema y puedan competir adecuadamente en el escenario internacional.

Sin embargo, para Hernández el desafío es más complejo:

"Se trata de fortalecer los procesos de integración regional, buscando mejorar la inserción internacional de América Latina. Es decir, es el momento de actualizar la noción de "Regionalismo Abierto", reforzando la complementariedad entre los procesos de integración a la economía mundial y los esquemas de integración regional o subregional". Hernández (2018, p. 156).

16 En el Perú incluso se habla de pequeñas y microempresas. 
La dificultad en este punto radica en que los países de América Latina que ya avanzaron significativamente en el proceso de desgravación arancelaria (y, por lo tanto, que ya hicieron el sacrificio mayor en sus economías) con diversos acuerdos de libre comercio o de asociación estratégica plenamente vigentes, de ninguna manera van a retroceder en lo ya ganado.

Se trata de procurar, con decisión política y creatividad, diferentes maneras para que los países que todavía mantienen altos niveles de protección arancelaria e incluso complejas medidas para-arancelarias, puedan acercarse, gradualmente, pero acercarse como objetivo a los niveles de apertura y competitividad de los países que ya avanzaron.

Recordemos nuevamente aquí lo que señalamos anteriormente en el sentido de que no hay claros puros ni oscuros puros, sino una variedad de grises. Al respecto, cuando el embajador peruano Allan Wagner era Director Secretario de la Junta del Acuerdo de Cartagena (el órgano ejecutivo de la Comunidad Andina), frente al estancamiento que se produjo en el logro de la Unión Aduanera por las diferencias en los niveles arancelarios de los Países Miembros, planteó lo que denominó "un arancel externo común flexible", de manera que ningún país retrocediera hacia una mayor protección y los más protegidos se comprometían a un proceso gradual pero firme de desgravación para acercarse a los niveles de los otros países socios. Lamentablemente, su posición no tuvo la acogida necesaria.

Hay que seguir reflexionando y haciendo propuestas para salir del entrampamiento y lograr una aproximación entre la situación de todos los países, pero, esta aproximación debe hacerse siempre buscando una mayor desgravación arancelaria, ganando eficiencia y competitividad, mirando al mundo.

De otro lado, hay mucho que trabajar en la región latinoamericana por buscar una mayor convergencia en la determinación de las normas de origen, las facilidades de acceso, procedimientos administrativos, infraestructura física, convenios aéreos, marítimos y de uso del espectro radioeléctrico, entre otros asuntos que le dan operatividad a la integración, y que permitirían que el ciudadano sienta que la integración lo beneficia realmente en su vida cotidiana.

Por ejemplo, con la construcción de la carretera Interoceánica Sur (IIRSA Sur), en la frontera del Perú con Brasil se logró conectar físicamente nueve departamentos del sur peruano con varios Estados del noroeste brasilero como Acre, Rondonia o Amazonas e incluso con Cobija en Bolivia.

Pero, cuando a través de una moderna carretera se cruza la frontera empiezan los problemas: las licencias de conducir, tarjetas de propiedad del vehículo y respectivas placas de rodaje no son aceptadas por las autoridades del otro país; ya los teléfonos celulares de los viajeros tienen que tener roaming internacional para poder usarse; y, si quisiéramos ir por avión del Cusco o Arequipa hacia el Acre o Rondonia o viceversa, primero hay que viajar a Lima o Sao Paulo y desde allí recién tomar un avión para el destino deseado, es decir, hay que recorrer grandes distancias para llegar a un Estado o región limítrofe por falta de acuerdos aéreos. ¿Dónde está entonces la integración más allá del discurso, del acuerdo o de las buenas intenciones?

En resumen, en el nuevo contexto mundial, global y competitivo, se ha avanzado en el acercamiento de posiciones entre multilateralismo y regionalismo; surgen nuevos y creativos bloques regionales de integración y se repotencian otros; se avanza también hacia una mayor integración mundial.

\section{¿En qué consiste la etapa de la integra- ción ciudadana que proponemos?}

Sin embargo, la calidad y sostenibilidad de los acuerdos de integración dependerá de los esfuerzos que se realicen para "aterrizar" los objetivos de la integración en la vida cotidiana de los ciudadanos y hacerlos partícipes -a ellos y a sus organizaciones- del propio diseño y puesta en práctica de las principales políticas por integración. De esto último trataremos en este último acápite, en el que-además- haremos una contribución al debate académico sobre el tema de la integración.

De esta manera, proponemos que el proceso de la integración se plantee en siete etapas: la Etapa Preliminar de concesiones preferenciales, 
la Zona de Libre Comercio, la Unión Aduanera, la Integración Ciudadana, el Mercado Común, la Unión Económica y la Integración Total (Ver: Tabla 14).

Incluimos entonces una nueva etapa -la de la integración ciudadana y de sus institucionesque consideramos debería procurarse antes de consolidar el mercado común, de manera de darle contenido social y sustento político desde la base al esfuerzo integrador.

Estamos convencidos que la integración, para poder ser sostenible social y políticamente, no sólo debe lograr la ampliación del mercado, la libre movilidad de factores productivos o la unificación de políticas, es decir, desde nuestro punto de vista, la sostenibilidad no depende solamente de empresarios, políticos o funcionarios públicos, sino también de ciudadanos convencidos de que son parte del proceso y que la integración les es de utilidad para su vida cotidiana.

Este es un tema que ya advertía Bela Balassa y lo denominaba "integración social", aunque no llegó a plantearlo como una etapa adicional. Decía Balassa: "La integración social no ha sido incluida en nuestra definición, ya que -si bien incrementa la efectividad de la integración económica- no es necesaria para las formas elementales de integración". Balassa (1964, p. 2).

En las primeras décadas del Siglo XXI, transcurrido ya un tiempo importante con diferentes experiencias de integración en el mundo, habría que decir que la integración social o "integración ciudadana" como nosotros la denominamos sí resulta crucial para lograr que el proceso de la integración se profundice y tenga mayor fortaleza para afrontar situaciones de eventuales crisis que no pongan en riesgo lo ya avanzado en el bloque regional. Seguramente, si el maestro Balassa fuera consultado sobre este planteamiento estuviera de acuerdo con él.

\section{Propuestas concretas para viabilizar la participación ciudadana}

La educación es, sin duda, uno de los motores propulsores fundamentales para avanzar y profundizar en los procesos de desarrollo de los países; también lo es para el avance de la integración.

Señala Vergara Estévez (1997), refiriéndose a América Latina:

"La educación para la integración es una de las áreas principales de cooperación cultural. Esta es necesaria, porque si bien existe en la región tendencias importantes hacia la integración, constatamos la existencia de diversos proyectos con orientaciones y objetivos diferentes $\mathrm{y}$, sobre todo, una cantidad importante de obstáculos de diverso tipo". Vergara (1997, p. 113).

Se trata de implementar una educación que también fomente la integración de los países y su importancia para la vida, desde los primeros

Tabla 14

Etapas de la Integración y grado de avance de algunos procesos de integración

\begin{tabular}{|c|c|c|}
\hline Bloques regionales & Etapas & Principal característica \\
\hline Etapa preliminar o Etapa "cero" & Negociación de mutuas preferencias & ALADI, APEC. \\
\hline Zona de Libre Comercio & Arancel Cero entre Países Miembros & $\begin{array}{l}\text { Diversos TLC's, TPP } \\
\text { Alianza del Pacífico }\end{array}$ \\
\hline Unión Aduanera & $\begin{array}{l}\text { Arancel externo común frente a terceros } \\
\text { Países }\end{array}$ & $\begin{array}{l}\text { Comunidad Andina } \\
\text { NAFTA, MCCA, } \\
\text { MERCOSUR }\end{array}$ \\
\hline Integración Ciudadana & Articulación de organizaciones de la sociedad civil en diversos campos & \\
\hline Mercado Común & Libre movilidad de todos los factores Productivos & ASEAN \\
\hline Unión Económica & Armonización de políticas monetarias y fiscales, entre otras & Unión Europea (UE) \\
\hline Integración Ciudadana & Articulación de organizaciones de la sociedad civil en diversos campos & \\
\hline Integración total & Unificación de políticas. Un solo gobierno. Una sola Constitución. & EE.UU. \\
\hline
\end{tabular}

Nota: Elaborado por el autor sobre la base de B. Balassa (1964), Cornejo (2010) y nuestra nueva propuesta. 
cursos escolares. Esta forma de educación para la integración se fundaría en el supuesto de que:

“...la acción integradora implica no sólo tener conciencia de las ventajas o efectos positivos que traen las distintas formas de asociación y de cooperación entre nuestras naciones, sino que requiere en la mayor medida posible, conocerse, valorarse y experimentar recíprocos sentimientos de cercanía y solidaridad". Vergara (1997, p. 113).

Dicho de otra manera, no se trata de decirle a los estudiantes que la integración es buena sino de experimentar, de manera concreta, que compartimos valores, historia, cultura y un destino común; que juntos podemos hacer mucho más y mejor que cada uno por su lado; $y$, que ello implica avanzar solidariamente y no "unos a costa de los otros" como parece suceder a veces.

Se trata entonces de impulsar la integración de unidades educativas de educación básica, técnica y superior entre los países integrantes del bloque regional de integración; activo intercambio de estudiantes y profesores, así como proyectos conjuntos de investigación y de proyección a la comunidad.

En la Tabla 15 incluimos algunas de los beneficios que, desde la educación, se pueden aprovechar para favorecer el proceso de integración.

\section{Tabla 15}

Beneficios que puede dar la educación para el proceso de integración

- Se pueden transmitir, desde el principio, valores que apunten a la acción conjunta, la solidaridad, la competitividad, el respeto por las normas y la importancia de preservar lo importante en el largo plazo.

- Trabajar desde el principio en la elaboración de una "historia común" de los países del bloque regional

- Los niños y jóvenes estudiantes en los colegios de los países miembros del bloque regional pueden conocer y experimentar los beneficios de la integración antes de ejercer la ciudadanía propiamente dicha.

- Un "currículo educativo regional" debe llevar a coordinar primero y unificar después los contenidos de materias que favorezcan la integración.

- Realización conjunta de actividades artísticas y culturales, a través de las cuales se promueva el esfuerzo integrador.

- $\quad$ Promoción de proyectos conjuntos de investigación científica y desarrollo tecnológico.

- Intercambio de estudiantes y pasantías en instituciones educativas en otros países del bloque regional.

Nota: Elaborado por el autor
La educación en valores que también favorezca la integración de los países nos parece fundamental. Valores como la puntualidad, la solidaridad, la competitividad, el respeto por los demás, el cumplimiento de las normas, los beneficios de actuar juntos, la importancia del largo plazo, deben estar presentes en la educación de los niños desde tempranos años en la educación básica.

$\mathrm{Al}$ interior del bloque regional, se hace necesario asimismo esforzarse por explicar y documentar la "historia común" entre los países miembros. Por ejemplo, en América Latina no sólo tenemos una historia común, sino también lenguas comunes y una cultura que compartimos. ${ }^{17}$

El esfuerzo pedagógico debe estar entonces en lograr que los jóvenes estudiantes de los varios países integrantes del bloque regional vayan conociendo y experimentando en forma concreta las ventajas de la integración para su vida diaria. Por ejemplo, que la zona de libre comercio o el mercado común les va a permitir mejores oportunidades de empleo y mayores ingresos, o que el pasaporte o la cédula de identidad común les va a permitir desplazarse libremente por los diferentes países miembros, o que la moneda única más adelante les va a reducir los costos de transacción y mejorar la eficiencia de los mercados.

Pero los esfuerzos de integración en materia educativa han sido insuficientes hasta el momento por lo menos en América Latina. Se han hecho algunos avances a nivel de educación superior universitaria, dando facilidades en las convalidaciones de cursos, permitiendo el intercambio de estudiantes y profesores y desarrollando investigaciones conjuntas. No ha sido suficiente.

El exministro de Educación del Perú, Dr. Víctor Raúl Díaz Chávez (2019) nos dice al respecto:

"A nivel de la educación básica hay que trabajar en tres aspectos sustanciales: la dotación de conocimientos, el desa-

17 Inclusive, como nos recuerda Víctor Raúl Díaz Chávez (Lima, 2019) “...tenemos en la región monumentos históricos originales como la ciudadela de Machu Picchu, que hoy se exhiben tal cual estaban en la época de los Incas, en comparación a monumentos en otras regiones del mundo que han tenido que ser restaurados por el paso del tiempo o por la destrucción de origen humano". 
rrollo de procedimientos y la generación de actitudes o valores favorables a la integración”. Díaz Chávez (2019)

En la integración europea se han realizado algunos esfuerzos en materia educativa. Por ejemplo, en 1999, los ministros de Educación de la Unión Europea y Rusia se reunieron en la ciudad italiana de Bolonia y firmaron la que se conoce como la "Declaración de Bolonia", mediante la cual se buscaba la convergencia para facilitar el intercambio de titulados universitarios y adaptar el contenido de los estudios universitarios a las exigencias de los nuevos tiempos.

Se trata de fomentar un sistema de grados académicos reconocibles y comparables a nivel europeo, con el objeto de propiciar la movilidad de estudiantes, docentes e investigadores, buscando siempre la calidad de la enseñanza superior.

La declaración empieza señalando:

"El proceso europeo, gracias a los logros extraordinarios de los últimos años, se ha convertido en una realidad cada vez más concreta y determinante en la vida de la Unión y de sus ciudadanos. Las perspectivas de ampliación y de intensificación de las relaciones con otros países europeos proporcionan a esa realidad unas dimensiones aún más amplias. Al mismo tiempo, estamos viendo una creciente concienciación, en muchas partes del mundo político-académico y en la opinión pública, de la necesidad de conferir a la construcción europea una articulación diferenciada y completa, reforzando sobre todo sus dimensiones intelectuales, culturales, sociales, científicas y tecnológicas". Declaración de Bolonia (1999).

La declaración resalta que es necesario trabajar por la competitividad de Europa y señala:

"Deberíamos analizar sobre todo el objetivo de incrementar la competitividad internacional del sistema europeo de enseñanza superior. La vitalidad y eficacia de cualquier civilización pueden medirse a través de la atracción que ejerce su cultura sobre otros países. Debemos asegurarnos de que el sistema europeo de enseñanza superior adquiera un grado de atracción que corresponda a nuestras extraordinarias tradiciones culturales y científicas". Declaración de Bolonia (1999).

Aun cuando la "Declaración de Bolonia" no es vinculante, llevó a la creación del denominado "Espacio Europeo de Educación Superior", como un marco de referencia para las reformas educativas que muchos países han decidido iniciar en los albores del Siglo XXI.

El Plan Bolonia deja prácticamente en manos de cada universidad el diseño de los grados; sólo se fijan unas directrices como que los estudios tienen que tener 240 créditos en total, 60 tienen que ser de enseñanzas básicas y deben tener un trabajo de fin de grado. Sin embargo, eso no quiere decir que cada universidad pueda hacer lo que quiera pues sus decisiones son siempre evaluadas por agencias dependientes de los respectivos Ministerios de Educación.

Este esfuerzo europeo es un avance (aun cuando no sea vinculante y la Unión Europea no tenga aún competencias en materia educativa) pero, nuevamente, está circunscrita al ámbito de la educación universitaria. En nuestra opinión, llegar con temas de integración a jóvenes de 20 años ya es tarde; el esfuerzo para ganar una "mentalidad a favor de la integración" debe empezar desde los primeros años de la escuela primaria.

\section{Como señala Vergara Estévez (1997):}

"En la mayor parte de los países la integración no está incorporada como tema en la educación secundaria, de pregrado y sólo tiene una modesta presencia en los estudios de postgrados". Vergara (1997, p. 138).

Pretendemos ir más allá. Proponemos la enseñanza de temas de la integración desde la educación primaria, con currículo, textos y contenidos pedagógicamente incluidos para ir formando, desde pequeños, en los estudiantes la idea de una "patria común", de un "destino común" más allá de su propio país, referente a la integración regional. 


\section{Los medios de comunicación y la inte- gración}

La integración no es un tema de "rating" y por eso, generalmente, los temas de la integración no aparecen en titulares ni en primeras planas de los principales medios de comunicación social, salvo que se trate de temas negativos en cuyo caso sí aparecen por excepción.

Si los ciudadanos y sus organizaciones se convierten en actores protagónicos y defensores del proceso de integración, entonces el tema estará en el "rating" y merecerá una atención especial por parte de los medios de comunicación. Mientras tanto, hay que diseñar estrategias comunicativas de todo tipo y principalmente a través de las redes sociales y las diferentes plataformas digitales para introducir el tema "integración" en el interés ciudadano.

\section{Las organizaciones de la Sociedad Civil y el proceso de integración}

El esfuerzo debe orientarse a contactar e interrelacionar entre sí de diferentes instituciones y organizaciones de la sociedad civil: agrupaciones de profesionales, gremios empresariales, organizaciones sindicales, iglesias, instituciones de voluntariado, instituciones deportivas, instituciones artísticas y culturales; en estos y otros casos el desafío es establecer plataformas de conexión y acción conjunta.

Representantes de estas instituciones civiles deben ser elegidos para formar parte de una Asamblea representativa de la Sociedad Civil de los países del bloque regional de integración, que tenga opinión vinculante sobre temas de interés conjunta y que actúe en coordinación con el Parlamento de la integración.

La integración tiene que dejar de ser un tema de especialistas, políticos y empresarios y ser parte del interés permanente del ciudadano común y de sus organizaciones.

\section{REFERENCIAS BIBLIOGRÁFICAS}

BALASSA, Bela (1964) “Teoría de la Integración Económica”; Unión Tipográfica Editorial Hispano-americana (UTEHA); México, 1964; Primera edición en español; Título del original en inglés: "The Theory of Economic Integration"; Traducción a cargo de Jorge Laris Casilla; 332 páginas.
BID (1992) "América Latina: el nuevo clima económico"; Madrid, julio de 1992; Cuarta Conferencia Bienal (pp. 38-39 y p. 133).

BOLÍVAR, Simón (1996) “Carta de Jamaica”; Archivo General de la Nación/Centro Nacional de la Historia; Quito- Ecuador, 1996; Página 16.

CASE, Karl E. / FAIR, Ray C. (1989) "Fundamentos de Economía”; Prentice Hall Hispanoamericana, S.A.; México, 1993; Segunda edición en español; Título del Original en inglés: "Principles of Economics” (1989); Página 989.

CHACHOLIADES, Miltiades (1992) "Economía Internacional”; Editorial McGraw-Hill; Bogotá-Colombia, marzo de 1992; Segunda Edición; Título del original en inglés: "International Economics"; Traductor: Carlos Arango; 674 páginas.

COMISIÓN ECONÓMICA PARA AMÉRICA LATINA (CEPAL) (1994) "El Regionalismo Abierto en América Latina y El Caribe"; CEPAL...; Santiago de Chile, enero de 1994; Página 8.

COMISIÓN ECONÓMICA PARA AMÉRICA LATINA Y EL CARIBE (CEPAL) (1994) "Políticas para mejorar la inserción en la economía mundial”; Santiago de Chile, 1994; Páginas 84-85.

CORNEJO RAMÍREZ, Enrique (2010) "Comercio Internacional: Hacia una gestión competitiva"; Editorial San Marcos; Lima, 2010; Cuarta edición; Primera edición en 1996; Página 235.

CORNEJO RAMÍREZ, Enrique (2012) “Globalización y Comercio Internacional"; Fondo Editorial de la Universidad Peruana Simón Bolívar (UPSB); Lima, mayo de 2012; Página 14.

CORNEJO RAMÍREZ, Enrique (2017) "El paso siguiente de la Globalización"; Fondo Editorial de la Universidad Peruana Simón Bolívar (UPSB); Lima, noviembre de 2017; Primera Edición; Página 22 .

DECLARACIÓN DE BOLONIA (1999) "Espacio Europeo de Educación Superior"; Bolonia-Italia; 19 de junio de 1999.

DÍAZ CHÁVEZ, Víctor Raúl (2019) “Entrevista con Enrique Cornejo"; Oficina del Vicerrectorado de la Universidad Peruana Simón Bolívar (UPSB); Lima, lunes 17 de junio de 2019, a las 12:30 pm.

Ffrench-Davis, Ricardo (1985) "Economía Internacional: Teorías y Políticas para el Desarrollo"; Fondo de Cultura Económica (FCE); Sección de Obras de Economía"; México, junio de 1985; Primera reimpresión; Primera edición en 1979; Página 412. 
GARCÍA R., Enrique (1997) “Nuevos Rumbos para la Integración ante el desafío de la Globalización"; Prólogo; Instituto Internacional de Integración del Convenio Andrés Bello"; La Paz-Bolivia, 1997; primera edición; Página “i”.

GARCÍA SORDÓ, Juan B. (2007) "Marketing Internacional”; McGraw Hill; México, 2007; Página 51.

GONZÁLEZ FERNÁNDEZ, Sara...; “El Impulso de la Integración económica en la década de los noventa"; ensayo publicado en libro titulado: "Temas de organización económica internacional"; Edit. McGraw Hill; Madrid, 1993; Página 222.

HELLER, H. Rober (1973) "Comercio Internacional: Teoría y Evidencia Empírica”; Biblioteca Tecnos de Ciencias Económicas; Madrid, 1973; Título de la versión original en inglés: "International Trade: Theory and Empirical Evidence" (1968); Reimpresión de la primera edición en español; Traductora Ana Sánchez Trujillo; 203 páginas.

HERNÁNDEZ, RENÉ (2018) "La Encrucijada de la Integración Regional y el Nuevo Regionalismo"; artículo publicado en Revista "Estudios de Políticas Públicas"; Volumen 4, Número 1; Universidad de Chile; Santiago de Chile, 2018; Sección "Artículos"; Páginas 149-159.

HETTNE, Björn (2002) “El Nuevo Regionalismo y el retorno a lo político"; artículo publicado en la Revista "Comercio Exterior"; Volumen 52, No. 11; México, noviembre de 2002; Página 955

KRUGMAN, Paul R.../ OBSTFELF, Maurice (1994) "Economía Internacional: Teoría y Práctica"; Editorial McGraw Hill; Madrid, 1994; Segunda Edición; Capítulo 9; Páginas 265-266. El título del original en inglés es: "International Economics. Theory and Policy" (1993).

MUÑIZ ORTEGA, Carlos (1986) “La Integración Económica de los Países Socialistas"; Ediciones Librería del Profesional; Bogotá-Colombia, 1986; Página 20.

OBSTFELF, Maurice (1994) "Economía Internacional: Teoría y Práctica”; Editorial McGraw Hill; Madrid, 1994; Segunda Edición; Capítulo 9; Páginas 265-266. El título del original en inglés es: "International Economics. Theory and Policy" (1993).

ORGANIZACIÓN MUNDIAL DEL COMERCIO (OMC) (1994) “Texto del Acuerdo GATT 1994”, Artículo XXIV; en Página Web oficial de la OMC: www. wto.org

REAL ACADEMIA ESPAÑOLA (2001) "Diccionario de la Lengua Española"; Editorial Espasa-Calpe S.A; Madrid-España, 2001; Vigésima Segunda Edición; Tomo II; Página 1288.
REBOLLEDO SOBERÓN, Luis (1993) “Apuntes sobre Integración"; artículo escrito en Libro titulado: "Esfuerzos de Integración en América Latina"; Editado por la Asociación de Facultades, Escuelas e Institutos de Economía de América Latina"; Lima, octubre de 1993; Imp. Talleres Gráficos de la Universidad de Lima; Página 6.

ROJAS VILLANUEVA, Javier (2013) “Integración Económica: Oportunidades de desarrollo para la pequeña y mediana empresa"; Fondo Editorial de la Universidad Nacional Mayor de San Marcos (UNMSM); Lima, julio de 2013; Primera edición; Página 46.

ROSALES, Osvaldo (2007) “Integración Regional: Propuestas de Renovación"; Reunión regional del Sistema Económico Latinoamericano (SELA); Caracas, julio de 2007; Diapositiva No. 10.

SALVATORE, Dominick (1992) "Economía Internacional”; Editorial McGraw-Hill; Bogotá-Colombia, enero de 1992; Tercera Edición; Título del original en inglés: "Theory and Problems of International Economics" (1977); Traductores: Gloria Rosas, Marco Tiznado y Bertha Rodríguez; 326 Páginas.

SCHETTINO, Macario (1996) "Economía Internacional”; Grupo Editorial Iberoamérica; México, mayo de 1996; Páginas 100-101.

SMITH, Adam (2009) "Una Investigación sobre la Naturaleza y Causas de la Riqueza de las Naciones"; Editorial Tecnos; Madrid, 2009; Título del original en inglés: "An inquiry into the Nature and Causes of the Wealth of Nations"; Traductor: Carlos Rodríguez Braun; Estudio Preliminar de Manuel Montalvo; Libro I, Capítulo1; Página 95.

STIGLITZ, Joseph E.... /CHARLTON, Andrew (2008) "Comercio Justo para todos"; Taurus Ediciones; Buenos Aires-Argentina, 2008; Título del original en inglés: "Fair Trade for All. How Trade can Promote Development" (2005); Traducción de Natalia Rodríguez Martín; Página 54.

STIGLITZ, Joseph E. (2018) "El malestar de la Globalización” (Revisitado); Penguin Random House Grupo Editorial; Barcelona-España, setiembre de 2018; Título del original en inglés: "Globalization and Its Discontents Revisited" (2002); Duodécima edición ampliada; Traducción de Carlos Rodríguez Braun y María Luisa Rodríguez Tapia; Página 64.

TUGORES QUES, Juan (1994) "Economía Internacional e Integración Económica”; Madrid, 1994; página 123. 
VERGARA ESTEVEZ, Jorge (1997) “Integración e Integración cultural. Hacia una Concepción renovada de la Integración en América Latina"; artículo publicado en: Instituto Internacional de Integración del Convenio "Andrés Bello" ...; "Nuevos Rumbos para la Integración ante el Desafío de la Globalización"; La Paz-Bolivia, 1997; Primera edición; Página 82.

VINER, Jacob... (1966) "Comercio Internacional y Desarrollo Económico"; Editorial Tecnos S.A., Madrid-España, 1966; Segunda edición; Colección de Ciencias Sociales; Serie de Economía; Título del original en inglés: "International Trade and Economic Development" (Oxford, 1953); Traducción Jacinto Ros; Página 23.
YOPO, Boris (2010) "La nueva Estrategia de Seguridad Nacional de Estados Unidos"; Programa de Cooperación en Seguridad Nacional de Estados Unidos; Fundación Friedrich Ebert Stiftung; Bogotá-Colombia, julio de 2010; Página 2. 